\title{
Reflexiones sobre la
}

normatividad que regula la información y la publicidad dirigida al consumidor menor de edad en Colombia y en España, haciendo énfasis en la publicidad para juguetes*

Some thoughts over the regulation of information and advertising addressed to minors acting as consumers in Colombia and Spain, with enphasis in toy's advertising

\author{
Adriana lucía López Alvarez ${ }^{* *}$
}

\section{RESUMEN}

El presente escrito consiste en un estudio comparado de la normatividad y la autorregulación en Colombia de la información y la publicidad dirigida a los

* Fecha de recepción: 29 de mayo de 2019. Fecha de aceptación: 27 de junio de 2019. Para citar el artículo: López A. "Reflexiones sobre la normatividad que regula la información y la publicidad dirigida al consumidor menor de edad en Colombia y en España, haciendo énfasis en la publicidad para juguetes". En Revist@ E-Mercatoria, vol. 18, n. ${ }^{\circ}$ 1, enerojunio, 2019. DOI: https://doi.org/10.18601/16923960.v18n1.04

** Abogada de la Universidad Externado de Colombia. Especialista en Derecho Comercial y Negocios Internacionales y Mercados de Capitales de la misma Universidad. Magíster Georgetown University. Docente investigadora del Departamento de Derecho Comercial de la Universidad Externado de Colombia. Correo electrónico: adriana.lopez@uexternado. edu.co 
menores de edad en su calidad de consumidores haciendo énfasis en la publicidad para juguetes, y de la autorregulación española de la publicidad infantil de juguetes; para terminar con una opinión sobre si la normativa colombiana en materia de regulación de la publicidad dirigida a los menores de edad haciendo énfasis en la publicidad para juguetes, es suficiente para lograr la efectiva protección de los derechos de estos en su calidad de consumidores.

Palabras Claves: menores consumidores, publicidad dirigida a menores, regulación de la publicidad para juguetes

\section{ABSTRACT}

This paper presents a comparative study of the colombian legislation and self regulation of information and advertising addressed to minors acting as consumers -making enphasis in advertising for toys-, and the spanish self regulation for advertising toys; to end with an opinion considering if the colombian norms concerning regulation of advertising addressed to minors with enphasis in advertising for toys, is enough and sufficient to achieve an effective protection for the minor's rights as consumers.

Key Words: Minors as consumers, advertising addressed to minors, regulation of toys advertising

\section{INTRODUCCIÓN}

Con la expedición de la Ley 1480 de 2011 conocida como el nuevo estatuto del consumidor, hemos visto como la regulación que protege al consumidor en Colombia se ha expandido notoriamente a campos que no se encontraban regulados en la normatividad anterior. Un ejemplo de esto es la protección que hoy en día se otorga a los niños, niñas y adolescentes (a quienes para efecto de este escrito denominaremos "menores de edad") en su calidad de consumidores.

En el escenario económico y social actual, es un factor innegable el hecho de que los menores de edad están jugando un papel preponderante dentro del mercado del consumo. Los menores de edad se han convertido en consumidores de productos y servicios, ya sea por adquisición directa de estos, o influenciando las decisiones de consumo de los adultos a cuyo cargo se encuentran.

Si observamos el Decreto 3466 de 1982 -anterior estatuto del consumidor-, éste no contenía en forma explícita ninguna protección enfocada a este segmento particular de consumidores. A diferencia del anterior, el nuevo estatuto del consumidor toma en consideración a los menores de edad, a los que además de reconocer su calidad de consumidores, les otorga una protección especial en atención a su vulnerabilidad. 
Justamente, por su condición vulnerable -la cual se deriva del hecho de no haber alcanzado aún la mayoría de edad como presupuesto mínimo para presumir su madurez como consumidores independientes e informados-, uno de los aspectos más relevantes a ser tenidos en cuenta dentro de la protección que se otorga a los menores consumidores, es la "publicidad" dirigida a estos, en la medida en que ésta puede influir en forma importante las decisiones de consumo de los menores, a quienes se presume como más influenciables que los consumidores adultos.

Partiendo de las anteriores consideraciones, el objetivo del presente escrito consiste en hacer un estudio sobre la normatividad y la autorregulación en Colombia de la información y la publicidad dirigida a los menores de edad en su calidad de consumidores haciendo énfasis en la publicidad para juguetes, hacer un estudio de la autorregulación española de la publicidad infantil de juguetes; comparar dichas regulaciones y hacer una reflexión sobre si la normativa colombiana vigente en materia de regulación de la publicidad dirigida a los menores de edad haciendo énfasis en la publicidad para juguetes, es suficiente para lograr la efectiva protección de los derechos de estos en su calidad de consumidores; para finalizar con el estudio del texto del Proyecto de Ley n. ${ }^{\circ} 233$ de 2017, que aunque tuvo ponencia negativa y no llegó a surtir primer debate, contiene una argumentación que nos invita a hacer un profundo cuestionamiento sobre si los niveles de protección que otorgan las leyes vigentes para la publicidad dirigida a menores son adecuados para la protección de estos, o si por el contrario, la publicidad dirigida a los menores debe ser prohibida en razón a su naturaleza abusiva, y en razón a que las decisiones de consumo de los niños deben estar en cabeza de los padres.

\section{REGULACIÓN EN COLOMBIA Y EN ESPAÑA EN MATERIA DE INFORMACIÓN Y PUBLICIDAD DIRIGIDA AL CONSUMIDOR MENOR DE EDAD, HACIENDO ÉNFASIS EN LA PUBLICIDAD PARA JUGUETES}

\subsection{Colombia}

Con la expedición de la Ley 1480 de 2011, la normatividad colombiana presentó un avance considerable en materia de protección al consumidor menor de edad, avance que se puede ver reflejado en primer lugar, en el hecho de que el nuevo estatuto le otorgó a los menores de edad la calidad de consumidores $;$ y en segundo lugar, en que el estatuto consagró una serie de protecciones para los menores en algunos temas particulares, dentro de los cuales se encuentra el tema de la publicidad dirigida a los niños, niñas y adolescentes.

Tomando en consideración que el anterior estatuto del consumidor -Decreto 3466 de 1982- ni siquiera mencionaba en su articulado a los menores de edad, el hecho de que la Ley 1480 aborde este tema permite afirmar que las 
disposiciones del nuevo estatuto reflejan la evolución que ha tenido la protección de los derechos de los menores de edad, esta vez desde la perspectiva del consumo.

En cuanto al tema particular que nos ocupa, la Ley 1480 tiene como uno de sus objetivos la protección "especial" de los menores en su calidad de consumidores-según lo establecido en el código de la infancia y la adolescencia-, y en el trascurso de su articulado consagra derechos tales como el derecho a recibir información, derecho a recibir protección contra la publicidad engañosa y derecho a informar, entre otros.

En concordancia con lo anterior, el Decreto 975 de 2014 -que reglamentó la Ley 1480 y que fue compilado en el capítulo 33 del Decreto 1074 del 26 de mayo de 2015 del Ministerio de Comercio, Industria y Turismo, "Por medio del cual se expide el Decreto Único Reglamentario del Sector Comercio, Industria y Turismo"-, se ocupó de regular los casos, el contenido y la forma en que se debe presentar la información y la publicidad dirigida a los menores de edad, constituyéndose esta ley y este decreto, en la normativa principal sobre publicidad dirigida a los menores de edad en Colombia.

Antes de entrar a analizar la Ley 1480 de 2011 y su Decreto reglamentario 975 de 2014 compilado en el capítulo 33 del Decreto 1074 de 2015, veamos los fundamentos constitucionales y legales en Colombia de la regulación de la publicidad dirigida a los menores de edad en su calidad de consumidores.

\subsubsection{Constitución Política}

La Constitución Política de Colombia consagra las bases de la protección a los menores de edad y de las características de la información que se suministra al público, especialmente en sus artículos $13,20,44,45$ y 78 .

Es así como el Decreto 975 de 2014 incluye como considerandos del mismo los artículos 44, 45 y 78 de la Constitución, al igual que a la Convención de las Naciones Unidas sobre los derechos del niño aprobada por la Ley 12 de 1991.

En los mencionados artículos de la Constitución, se consagran el derecho fundamental a la igualdad, el derecho fundamental a la libertad de expresión e información, los derechos fundamentales de los niños, el derecho a la protección y a la formación integral del adolescente y la obligación legal de regular el control de calidad de bienes y servicios prestados a la comunidad y la información que debe suministrarse al público en su comercialización.

Veamos estos derechos y obligaciones con más detalle:

\section{Derecho a la igualdad}

El Artículo 13 de la Constitución Política consagra el derecho fundamental a la libertad y a la igualdad de las personas, disponiendo a su vez que el Estado promoverá las condiciones para que esta igualdad sea "real y efectiva" y 
protegiendo especialmente a aquellas personas que, por su condición económica, física o mental, se encuentren en circunstancia de debilidad manifiesta. Veamos el texto del artículo:

\begin{abstract}
"Artículo 13. Todas las personas nacen libres e iguales ante la ley, recibirán la misma protección y trato de las autoridades y gozarán de los mismos derechos, libertades y oportunidades sin ninguna discriminación por razones de sexo, raza, origen nacional o familiar, lengua, religión, opinión política ofilosófica. El Estado promoverá las condiciones para que la igualdad sea real y efectiva y adoptará medidas en favor de grupos discriminados o marginados. El Estado protegerá especialmente a aquellas personas que por su condición económica, física o mental, se encuentren en circunstancia de debilidad manifiesta y sancionará los abusos o maltratos que contra ellas se cometan"1.
\end{abstract}

\title{
Derecho a la Libertad de expresión e información
}

El artículo 20 de la Constitución Política consagra el derecho fundamental a la libertad de expresión e información, estableciendo que toda persona tiene libertad de expresar su pensamiento al igual que libertad de informar y recibir información. Veamos el texto del artículo:

\begin{abstract}
"Artículo 20. Se garantiza a toda persona la libertad de expresar y difundir su pensamiento y opiniones, la de informar y recibir información veraz e imparcial, y la de fundar medios masivos de comunicación. Estos son libres y tienen responsabilidad social. Se garantiza el derecho a la rectificación en condiciones de equidad. No babrá censura"2.
\end{abstract}

\section{Derechos fundamentales de los niños}

El artículo 44 de la Constitución además de consagrar los derechos mínimos de los niños dentro de los cuales se encuentran el derecho a la vida, integridad física y salud entre otros, radica en cabeza de la familia, la sociedad y el Estado la obligación de asistir y proteger al niño para garantizar su desarrollo integral. El artículo 44 consagra estos derechos de los niños así:

"Artículo 44.- Son derechos fundamentales de los niños: la vida, la integridad física, la salud y la seguridad social, la alimentación equilibrada, su nombre y nacionalidad, tener una familia y no ser separados de ella, el cuidado y amor, la educación y la cultura, la recreación y la libre expresión de su opinión. Serán protegidos contra toda forma de abandono, violencia física o moral, secuestro, venta, abuso sexual, explotación laboral o económica y trabajos riesgosos. Gozarán también de los demás derechos consagrados en la Constitución, en las leyes y en los tratados internacionales ratificados por Colombia. La familia, la sociedad y el Estado tienen la obligación de asistir y proteger al niño para garantizar su desarrollo armónico e integral y el ejercicio pleno

1 República de Colombia. Constitución Política de 1991. Artículo 13

2 Ibíd. Artículo 20. 
de sus derechos. Cualquier persona puede exigir de la autoridad competente su cumplimiento y la sanción de los infractores. Los derechos de los niños prevalecen sobre los derechos de los demás"3.

\section{Derechos de los adolescentes}

El artículo 45 de la Constitución Política consagra los derechos de los adolescentes a la protección y formación integral como se ve a continuación:

"Artículo 45. El adolescente tiene derecho a la protección y a la formación integral. El estado y la sociedad garantizan la participación activa de los jóvenes en los organismos públicos y privados que tengan a cargo la protección, educación y progreso de la juventud"4.

Información que debe suministrarse al público en la comercialización de bienes y servicios

En cuanto a la información que debe suministrarse al público en la comercialización de bienes y servicios y la obligación legal de regular el control de calidad en la comercialización de los mismos, el Artículo 78 de la Constitución dispone lo siguiente:

\footnotetext{
"Artículo 78: La ley regulará el control de calidad de bienes y servicios of recidos y prestados a la comunidad, así como la información que debe suministrarse al público en su comercialización. Serán responsables, de acuerdo con la ley, quienes en la producción y en la comercialización de bienes y servicios, atenten contra la salud, la seguridad y el adecuado aprovisionamiento a consumidores y usuarios. El estado garantizará la participación de las organizaciones de consumidores y usuarios en el estudio de las disposiciones que les conciernen. Para gozar de este derecho las organizaciones deben ser representativas y observar procedimientos democráticos internos".
}

Vemos entonces como la Constitución colombiana provee las bases para la protección de los menores de edad, al hacerlos sujetos de derechos y de la protección en cabeza de la familia, la sociedad y el Estado, para garantizar así su desarrollo y su formación integral. Dentro de estos derechos, es importante resaltar el derecho consagrado en el artículo 20 a la libertad de expresión e información, donde se establece el derecho fundamental que tienen todas las personas, incluyendo a los menores, de expresar y difundir su pensamiento, y de informar y recibir información veraz e imparcial.

De otra parte, la Constitución contiene la obligación de regular el control de calidad de los bienes y servicios ofrecidos a la comunidad y de la información que debe suministrarse al público -incluidos los menores de edad-en su comercialización, sentándose así la base para la regulación de la información 
que debe suministrarse a los menores de edad en su calidad de consumidores, atendiendo los demás postulados constitucionales y legales que consagran la protección especial a este segmento de la población.

\subsubsection{Ley 12 de 1991-Convención de las Naciones Unidas sobre los Derechos del Niño}

La Convención de las Naciones Unidas sobre los Derechos del Niño aprobada a través de la Ley 12 de 1991, contiene en su Preámbulo varias consideraciones, dentro de las cuales resaltamos en forma resumida las siguientes, por estimarlas relacionadas con el tema objeto de estudio:

- "(...) que la infancia tiene derecho a cuidados y asistencia especiales, (...)

- (...) que la necesidad de proporcionar al niño una protección especial ba sido enunciada en la Declaración de Ginebra de 1924 sobre los Derechos del Niño y en la Declaración de los Derechos del Niño adoptada por la Asamblea General el 20 de noviembre de 1959, y reconocida en la Declaración Universal de Derechos Humanos, en el Pacto Internacional de Derechos Civiles y Políticos (en particular, en los artículos 23 y 24), en el Pacto Internacional de Derechos Económicos, Sociales y Culturales (en particular, en el artículo 10) y en los estatutos e instrumentos pertinentes de los organismos especializados y de las organizaciones internacionales que se interesan en el bienestar del niño (...),

- (...) el niño, por su falta de madurez física y mental, necesita protección y cuidado especiales, incluso la debida protección legal, tanto antes como después del nacimiento (... $)^{\prime \prime}$.

Además de las anteriores consideraciones donde se destacan los derechos y la protección especial que deben recibir los niños en atención a su falta de madurez física y mental, el articulado de la Ley 12 de 1991 se ocupa de diversos temas relacionados con estos derechos y protecciones especiales, dentro de los cuales resaltamos los contenidos en el artículo 17, que hace parte de los considerandos del Decreto 975 de 2014 que reglamenta los casos, el contenido y la forma en que se debe presentar la información y la publicidad dirigida a los menores de edad en su calidad de consumidores. Veamos el texto de este artículo:

"Artículo 17. Los Estados Partes reconocen la importante función que desempeñan los medios de comunicación y velarán por que el niño tenga acceso a información y material procedentes de diversas fuentes nacionales e internacionales, en especial la información y el material que tengan

6 Republica de Colombia. Congreso de la República. Ley 12 (22, enero, 1991). Por medio de la cual se aprueba la Convención sobre los Derechos del Niño adoptada por la Asamblea General de las Naciones Unidas el 20 de noviembre de 1989. 
por finalidad promover su bienestar social, espiritual y moral y su salud física y mental. Con tal objeto, los Estados Partes: a) Alentarán a los medios de comunicación a difundir información y materiales de interés social y cultural para el niño, de conformidad con el espíritu del artículo $29 ;$ b) Promoverán la cooperación internacional en la producción, el intercambio y la difusión de esa información y esos materiales procedentes de diversas fuentes culturales, nacionales e internacionales; c) Adelantarán la producción y difusión de libros para niños; d) Adelantarán a los medios de comunicación a que tengan particularmente en cuenta las necesidades linguísticas del niño perteneciente a un grupo minoritario o que sea indígena, e) Promoverán la elaboración de directrices apropiadas para proteger al niño contra toda información y material perjudicial para su bienestar, teniendo en cuenta las disposiciones de los artículos 13 y $18^{\prime \prime 7}$.

Del contenido del artículo 17 observamos como los Estados parte de la Convención reconocen la importancia de los medios de comunicación y el papel que estos pueden jugar en la promoción del bienestar y la salud de los menores, comprometiéndose a velar porque el niño tenga acceso a información y material procedente de diversas fuentes, en especial que busque promover su bienestar y su salud, a alentar a los medios de comunicación a difundir información de interés social y cultural para el niño, a promover la cooperación internacional en la producción, intercambio y difusión de esa información, a adelantar la producción y difusión de libros para niños, y a promover la elaboración de directrices para la protección de los niños contra la información perjudicial para su bienestar.

Se observa entonces como el acceso a la información se constituye en un derecho de los niños, sobre todo cuando esta información promueva su bienestar y su salud; al igual que vemos como los niños deben ser protegidos contra la información que les resulte perjudicial.

\subsubsection{Ley 1480 de 2011}

Tal como lo mencionábamos anteriormente, la Ley 1480 de 2011 ha representado una importante evolución normativa frente a la protección de los consumidores, y en particular, de los consumidores menores de edad.

Esta evolución de la legislación colombiana se ve reflejada desde el artículo primero de la mencionada ley, el cual contiene los principios generales orientadores del estatuto, y permite vislumbrar de alguna manera el espíritu del mismo, pues el estatuto además de regular los temas propios de la protección al consumidor y sus derechos, considera en su ámbito temas específicos como el acceso del consumidor a la información adecuada que le permita hacer elecciones bien fundadas, la educación del consumidor, la protección de los consumidores frente a riesgos para su salud y seguridad, la libertad de 
los consumidores para organizarse, y por supuesto, la protección especial a los niños, niñas y adolescentes en su calidad de consumidores.

Veamos entonces el contenido del artículo primero de la Ley 1480 de 2011:

"Artículo 1. Principios generales. Esta ley tiene como objetivos proteger, promover y garantizar la efectividad y el libre ejercicio de los derechos de los consumidores, así como amparar el respeto a su dignidad y a sus intereses económicos, en especial, lo referente a:

1. La protección de los consumidores frente a los riesgos para su salud y seguridad.

2. El acceso de los consumidores a una información adecuada, de acuerdo con los términos de esta ley, que les permita bacer elecciones bien fundadas.

3. La educación del consumidor

4. La libertad de constituir organizaciones de consumidores y la oportunidad para estas organizaciones de bacer oír sus opiniones en los procesos de adopción de decisiones que las afecten.

5. La protección especial a los niños, niñas y adolescentes, en su calidad de consumidores, de acuerdo con lo establecido en el Código de la Infancia y la Adolescencia"8.

En cuanto al tema que nos ocupa, el artículo primero toca dos aspectos que consideramos se relacionan con este en forma directa. El primer aspecto se encuentra contenido en el numeral 5, donde el legislador protege la efectividad y libre ejercicio de los derechos y ampara la dignidad e intereses económicos de los consumidores menores de edad, al consagrar "(...) la protección especial a los niños, niñas y adolescentes, en su calidad de consumidores, de acuerdo con lo establecido en el Código de la Infancia y la Adolescencia"9.

Aquí se manifiesta como el legislador reconoce a los niños, niñas y adolescentes la calidad de consumidores, lo cual constituye un importante avance de esta legislación en comparación con las leyes que le anteceden. Este reconocimiento como veremos es importante para lograr que, desde la perspectiva del consumo, este segmento de la población goce en forma efectiva de la protección especial que la ley le concede.

El otro aspecto contenido en el artículo primero, que se relaciona directamente con nuestro tema de estudio, se encuentra consagrado en el numeral 2 que ampara el acceso de los consumidores a una información adecuada que les permita hacer elecciones bien fundadas.

8 República de Colombia. Congreso de la República. Ley 1480 (12, octubre, 2011). Por medio de la cual se expide el Estatuto del Consumidor y se dictan otras disposiciones. Artículo 1.

$9 \quad$ Ibíd. Artículo 1, numeral 5. 
La "información" es de suma importancia dentro de la Ley 1480, tanto así que su título quinto se ocupa exclusivamente de este tema. Sin embargo, el tema de la información también es abordado en otros artículos que no pertenecen al título quinto de la ley, tales como los artículos 3 y 5 . En cuanto a la información dirigida a los menores de edad, vemos como los artículos 28 y 52 -este último sobre comercio electrónico-, están relacionados con este segmento especial de la población.

Respecto a la información, en la Ley 1480 aparece en primer término el artículo 3, el cual establece los derechos y deberes de los consumidores y usuarios, y cuyo numeral 1.3 consagra el derecho a recibir información de la siguiente manera:

"1.3 Derecho a recibir información: Obtener información completa, veraz, transparente, oportuna, verificable, comprensible, precisa e idónea respecto de los productos que se ofrezcan o se pongan en circulación, así como sobre los riesgos que puedan derivarse de su consumo o utilización, los mecanismos de protección de sus derechos y las formas de ejercerlos"10.

Es relevante el hecho de que la ley cualifique el tipo de información al que tiene derecho el consumidor. No resulta suficiente entonces que el consumidor reciba información genérica sobre los productos que le son ofrecidos, sino que esta información debe cumplir con los requisitos de ser completa, veraz, transparente, oportuna, verificable, comprensible, precisa e idónea. Subrayamos la palabra comprensible, al considerar que esta característica es de especial importancia cuando estamos hablando de consumidores menores

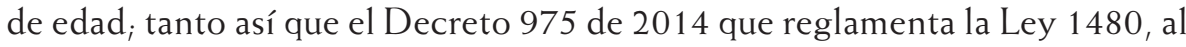
consagrar en su artículo 4 los deberes del anunciante respecto a la información y publicidad dirigida a los menores, establece que "toda información y publicidad dirigida a niños, niñas y adolescentes deberá ser respetuosa de sus condiciones de desarrollo mental, madurez intelectual y comprensión media propias de personas de su edad" (... $)^{11}$.

De otra parte, en el artículo 5 de la Ley 1480 se definen varios términos para efectos de la ley, dentro de los cuales resaltamos los consignados en los numerales 7, 12 y 13, donde el numeral 7 define el término "información", el numeral 12 define el término "publicidad", y el numeral 13 define el término "publicidad engañosa".

10 Ibíd. Artículo 3, numeral 1.3.

11 República de Colombia. Ministerio de Comercio, Industria y Turismo. Decreto 975 (28, mayo, 2014). Por el cual se reglamentan los casos, el contenido y la forma en que se debe presentar la información y la publicidad dirigida a los niños, niñas y adolescentes en su calidad de consumidores. Artículo 4; compilado en el artículo 2.2.2.33.4 del Decreto 1074 (26, mayo, 2015), Ministerio de Comercio, Industria y Turismo. Por medio del cual se expide el Decreto Único Reglamentario del Sector Comercio, Industria y Turismo. 
El término "información" es definido como "(...) 7. Información: Todo contenido $y$ forma de dar a conocer la naturaleza, el origen, el modo de fabricación, los componentes, los usos, el volumen, peso o medida, los precios, la forma de empleo, las propiedades, la calidad, la idoneidad o la cantidad, y toda otra característica o referencia relevante respecto de los productos que se ofrezcan o pongan en circulación, así como los riesgos que puedan derivarse de su consumo o utilización"12.

El término "publicidad" es definido como "(... 12. Publicidad: Toda forma y contenido de comunicación que tenga como finalidad influir en las decisiones de consumo"13, y el término "publicidad engañosa" se define como "(...) 13. Publicidad engañosa: Aquella cuyo mensaje no corresponda a la realidad o sea insuficiente, de manera que induzca o pueda inducir a error, engaño o confusión"14.

Ya entrando en el Título V "De la Información", el artículo 23 de la Ley 1480 habla de la información mínima que deben suministrar a los consumidores los proveedores y productores, y la responsabilidad derivada de dicho suministro de información, cuando establece:

\footnotetext{
"Art. 23. Información mínima y responsabilidad. Los proveedores y productores deberán suministrar a los consumidores información clara, veraz, suficiente, oportuna, verificable, comprensible, precisa e idónea sobre los productos que ofrezcan y, sin perjuicio de lo señalado para los productos defectuosos, serán responsables de todo daño que sea consecuencia de la inadecuada o insuficiente información. En todos los casos la información minima debe estar en castellano. (...)"15.
}

De la lectura del artículo 23 se desprende una coincidencia casi total con el numeral 1.3 del artículo 3 de la misma ley, en cuanto a los términos utilizados para enunciar las características que debe tener la información que reciba el consumidor. El numeral 1.3 del artículo 3 habla de información "completa, veraz, transparente, oportuna, verificable, comprensible, precisa e idónea", respecto a los productos ofrecidos y los riesgos que puedan derivarse de estos; y el artículo 23 habla de información "clara, veraz, suficiente, oportuna, verificable, comprensible, precisa e idónea" sobre los productos ofrecidos. Consideramos que las pocas diferencias entre estos dos artículos son más de forma que de fondo, pues ambos abarcan los mismos conceptos fundamentales y cubren los mismos aspectos, reiterando la intención de la ley de exigir que la información cumpla con unas características mínimas determinadas para considerarse información idónea para tomar decisiones de consumo.

12 República de Colombia. Congreso de la República. Ley 1480 (12, octubre, 2011). Por medio de la cual se expide el Estatuto del Consumidor y se dictan otras disposiciones. Artículo 5, numeral 7. 
Así mismo, el artículo 24 continúa desarrollando el contenido que debe tener la información suministrada a los consumidores, y específicamente el contenido que debe tener la información mínima que debe suministrar tanto el productor como el proveedor.

Según se desprende de lo dispuesto en el numeral 1 del artículo 24, la información mínima que debe suministrar el productor está encaminada, en términos generales, a que el consumidor reciba instrucciones de uso o consumo, conservación e instalación del producto o servicio, cantidad peso o volumen de ser aplicable, fechas de vencimiento de ser aplicables y especificaciones del bien o servicio.

En cuanto a la información mínima que debe suministrar el proveedor, el numeral 2 del artículo 24 dispone que esta es aquella relativa a las garantías que asisten al co<nsumidor o usuario y al precio de los bienes o servicios.

En cuanto a la posibilidad de que el productor o el proveedor se exoneren de responsabilidad, el parágrafo del artículo 24 establece que éstos solo podrán exonerarse en caso de demostrar fuerza mayor, caso fortuito o que la información fue adulterada o suplantada sin haber podido evitarlo.

Los artículos 25 al 27 siguen desarrollando el tema referente a la "información" a ser suministrada a los consumidores, tocando aspectos como la información relativa a productos que sean nocivos para la salud, la información relativa a los precios de venta al público y las constancias de las operaciones de consumo que se realicen; llegando así hasta el artículo 28, el cual tiene conexión directa con el tema de la información a ser provista a los menores de edad.

El artículo 28 establece lo siguiente: "Art. 28. Derecho a la información de los niños, niñas y adolescentes. El Gobierno Nacional reglamentará, en el término de un año a partir de la entrada en vigencia de la presente ley, los casos, el contenido y la forma en que deba ser presentada la información que se suministre a los niños, niñas y adolescentes en su calidad de consumidores, en desarrollo del derecho de información consagrado en el artículo 34 de la Ley 1098 de $2006^{\prime \prime 16 . ~}$

El derecho a la información al que hace mención el artículo 28, es aquel consagrado en el artículo 34 de la Ley 1098 de 2006, Código de la Infancia y la Adolescencia. Este código en su artículo 34 consagra así, el derecho a la información de los niños, niñas y adolescentes:

"Artículo 34. Derecho a la Información: Sujeto a las restricciones necesarias para asegurar el respeto de sus derechos y el de los demás y para proteger la seguridad, la salud y la moral, los niños, las niñas y los adolescentes tienen derecho a buscar, recibir y difundir información e ideas a través de los distintos medios de comunicación de que dispongan"17.

17 República de Colombia. Congreso de la República. Ley 1098 (8, noviembre, 2006). Por la cual se expide el Código de la Infancia y la Adolescencia. Artículo 34. 
Según se desprende del tenor del artículo 34, es un derecho de los menores de edad el recibir, buscar y difundir información e ideas a través de los medios de comunicación de que dispongan. Sin embargo, este derecho de los menores no es un derecho absoluto, sino que se encuentra sujeto a las restricciones que aseguren el respeto de los derechos de los menores y el de los demás, y la protección de la seguridad, la salud y la moral de los mismos.

En cuanto a la obligación consagrada en el artículo 28 de la Ley 1480 de reglamentar el derecho a la información de los menores de edad, esta se cumplió con la expedición del Decreto 975 del 28 de mayo de 2014, "por el cual se reglamentan los casos, el contenido y la forma en que se debe presentar la información y la publicidad dirigida a los niños, niñas y adolescentes en su calidad de consumidores", del cual hablaremos más adelante.

El otro aspecto directamente relacionado con el tema de la información es la publicidad. La publicidad es tratada en el Título VI de la Ley 1480, artículos 29 al 33, pero hay referencias a esta en otros artículos de la ley entre los cuales se encuentran los artículos 3 y 5 .

El artículo 3 de la Ley 1480 -contentivo de los derechos y deberes de los consumidores y usuarios-, consagra en su numeral 1.4 el derecho a recibir protección contra la publicidad engañosa. A su vez, el artículo 5 de la ley define los términos "publicidad" y "publicidad engañosa".

En cuanto a la "publicidad", tal como ya lo habíamos mencionado anteriormente, el numeral 12 del artículo 5 de la Ley 1480 la define como "(...) Toda forma y contenido de comunicación que tenga como finalidad influir en las decisiones de consumo"; y el numeral 13 del mismo artículo define el término "publicidad engañosa" como "(...) Aduella cuyo mensaje no corresponda a la realidad o sea insuficiente, de manera que induzca o pueda inducir a error, engaño o confusión".

De la definición del término "publicidad", se puede inferir el papel preponderante que esta puede tener cuando es dirigida al segmento de los menores de edad, considerando que la finalidad de la publicidad es influenciar las decisiones de consumo. Todo aquello que tenga la potencialidad de influenciar las decisiones de un menor de edad debe tener una consideración especial, dada la inmadurez del menor para tomar decisiones y la especial protección de la que es sujeto.

Aunque el Título VI de la Ley 1480 sobre Publicidad no se refiere en particular a la publicidad dirigida a los menores de edad, esta fue objeto de reglamentación especial a través de la expedición del Decreto 975 de 2014, el cual estudiaremos a continuación. 


\subsubsection{Decreto 975 de 2014, compilado en el Capítulo 33 del Decreto 1074 del 26 de mayo de 2015 del Ministerio de Comercio, Industria y Turismo, "Por medio del cual se expide el Decreto Único Reglamentario del Sector Comercio, Industria y Turismo"}

A continuación, haremos un breve repaso del contenido general del Decreto 975 de 2014 "Por el cual se reglamentan los casos, el contenido y la forma en que se debe presentar la información y la publicidad dirigida a los niños, niñas y adolescentes en su calidad de consumidores", decreto que fue compilado en el capítulo 33 del Decreto 1074 de 2015 del Ministerio de Comercio Industria y Turismo "Por medio del cual se expide el Decreto Único Reglamentario del Sector Comercio, Industria y Turismo".

Este decreto contiene las normas que regulan la información y publicidad dirigida a los consumidores menores de edad por cualquier medio (impreso, electrónico, audiovisual, auditivo, etc.), siendo aplicable tal como lo indica su artículo segundo, a las relaciones de consumo, a la responsabilidad de los productores, proveedores y a quienes intervengan en el suministro de información a los menores en su calidad de consumidores.

El Decreto 975 reglamenta el artículo 28 de la Ley 1480 de 2011, y recoge en sus considerandos los artículos 44, 45 y 78 de la Constitución, la Ley 12 de 1991 en su artículo 17, la Ley 1480 de 2011 en sus artículos 1, 3 y 28, y establece en su último considerando lo siguiente: "(...) Que por lo anterior, se bace necesario reglamentar los casos, el contenido y la forma en la que se deben presentar la información y la publicidad que se dirija a los niños, niñas y adolescentes en su calidad de consumidores, de una manera apropiada para su edad, que evite que sean indebidamente influenciados en la toma de decisiones de consumo y que asegure el respeto de sus derechos constitucionales" $^{\prime 18}$. (lo subrayado es nuestro)

Este último considerando es de especial importancia pues contiene tres lineamientos para la presentación de la información y la publicidad dirigida a los menores de edad en su calidad de consumidores, siendo estos los siguientes:

i. Debe presentarse de manera apropiada para su edad,

ii. Debe evitar influenciar indebidamente la toma de decisiones de consumo del menor, $y$

iii. Debe asegurar el respeto a los derechos constitucionales de los menores

18 República de Colombia. Ministerio de Comercio, Industria y Turismo. Decreto 975 (28, mayo, 2014). Por el cual se reglamentan los casos, el contenido y la forma en que se debe presentar la información y la publicidad dirigida a los niños, niñas y adolescentes en su calidad de consumidores; compilado en el capítulo 33 del Decreto 1074 (26, mayo, 2015), Ministerio de Comercio, Industria y Turismo. Por medio del cual se expide el Decreto Único Reglamentario del Sector Comercio, Industria y Turismo. 
En cuanto a las características de la información a ser dirigida a los menores, el artículo 3 del Decreto 975, compilado en el artículo 2.2.2.33.3 del Decreto 1074 de 2015, contiene los derechos de estos frente a la información y la publicidad, estableciendo que la información dirigida a los menores deberá ser "clara, veraz, suficiente, oportuna, verificable, comprensible, precisa e idónea" y que toda forma y contenido de comunicación que tenga por finalidad influir en las decisiones de consumo de los menores no podrá inducir a error, engaño o confusión. Así mismo, este artículo establece que los anuncios publicitarios dirigidos a los menores de edad no podrán contener ninguna forma de violencia, discriminación, acoso, o cualquier conducta que pueda afectar la vida o integridad física de una persona ${ }^{19}$.

Como vemos, las características que debe tener la información dirigida a los menores de edad coinciden con las características que debe tener la información mínima que los proveedores y productores deben suministrar a los consumidores, según lo establecido en el artículo 23 de la Ley 1480. Sin embargo, el Decreto 975 no se limita a establecer las características de la información, sino que va más allá al establecer cuáles son los derechos de los menores frente a la información y publicidad, y los deberes del anunciante respecto a la información y publicidad dirigida a los menores.

La siguiente es una tabla donde se resumen estos derechos y deberes, los cuales se encuentran consagrados en los artículos 3 y 4 del Decreto 975, compilados en los artículos 2.2.2.33.3 y 2.2.2.33.4 del Decreto $1074^{[20]}$ :

DERECHOS DE LOS MENORES FRENTE A LA INFORMACIÓN QUE SE LES DIRIJA Y DEBERES DEL ANUNCIANTE RESPECTO A LA INFORMACION Y PUBLICIDAD DIRIGIDA A LOS MENORES DE EDAD

\begin{tabular}{|l|l|}
\hline \multicolumn{1}{|c|}{ DERECHOS de los menores } & \multicolumn{1}{c|}{ DEBERES de los anunciantes } \\
\hline $\begin{array}{l}\text { La información debe ser clara, } \\
\text { veraz, suficiente, oportuna, } \\
\text { verificable, comprensible, precisa } \\
\text { e idónea }\end{array}$ & $\begin{array}{l}\text { La información y publicidad dirigida a menores debe respetar } \\
\text { las condiciones de desarrollo mental, madurez intelectual y } \\
\text { comprensión media propias de personas de su edad, por lo que el } \\
\text { anunciante debe cumplir con las siguientes condiciones: }\end{array}$ \\
\hline \multirow{2}{*}{$\begin{array}{l}\text { La forma y contenido de } \\
\text { comunicación que busque influir } \\
\text { decisiones de consumo no podrá } \\
\text { inducir a error, engaño o confusión }\end{array}$} & $\begin{array}{l}\text { - La información y publicidad debe evitar imágenes, textos, } \\
\text { expresiones visuales o auditivas o representaciones que no } \\
\text { correspondan a la realidad del producto en su funcionamiento o } \\
\text { características }\end{array}$ \\
\cline { 2 - 2 } & $\begin{array}{l}\text { En la información o publicidad que exponga el funcionamiento } \\
\text { o uso de un producto, se prohíbe: a) indicar o representar una } \\
\text { edad diferente a la requerida para que el menor ensamble las } \\
\text { piezas u opere el producto; b) exagerar el verdadero tamaño, }\end{array}$ \\
\hline
\end{tabular}

19 Ibíd. Decreto 975 de 2014 Artículo 3, compilado en el Artículo 2.2.2.33.3 del Decreto 1074 de 2015

20 Ibíd. Decreto 975 de 2014. Artículos 3 y 4, compilados en los Artículos 2.2.2.33.3 y 2.2.2.33.4 del Decreto 1074 de 2015 


\begin{tabular}{|c|c|}
\hline DERECHOS de los menores & DEBERES de los anunciantes \\
\hline & $\begin{array}{l}\text { naturaleza, durabilidad y usos del producto } ; \text { c) no informar } \\
\text { que las baterías o accesorios mostrados en el anuncio no están } \\
\text { incluidos en el empaque del producto o se venden por separado; } \\
\text { d) no informar que para el funcionamiento de un producto se } \\
\text { requiere baterías o elementos complementarios }\end{array}$ \\
\hline & $\begin{array}{l}\text { - Cuando se anuncie un bien o servicio cuya adquisición } \\
\text { requiera llamadas o mensajes de texto o multimedia que tengan } \\
\text { un costo, deberá informarse su valor y advertir al menor que } \\
\text { previa a la llamada o mensaje, debe solicitar autorización de sus } \\
\text { padres }\end{array}$ \\
\hline \multirow{5}{*}{$\begin{array}{l}\text { Los anuncios publicitarios no } \\
\text { contendrán ninguna forma de } \\
\text { violencia, discriminación, acoso } \\
\text { o cualquier conducta que pueda } \\
\text { afectar la vida o integridad física de } \\
\text { una persona }\end{array}$} & $\begin{array}{l}\text { - La información o publicidad no debe contener imágenes o } \\
\text { información de contenido sexual, violento, discriminatorio o que } \\
\text { promueva conductas contrarias a la moral y buenas costumbres }\end{array}$ \\
\hline & $\begin{array}{l}\text { - La información o publicidad no debe contener imágenes o } \\
\text { información relacionada con el consumo de estupefacientes y/o } \\
\text { bebidas alcohólicas, salvo se trate de campañas de prevención }\end{array}$ \\
\hline & $\begin{array}{l}\text { - La información o publicidad no debe usar imágenes, textos, } \\
\text { expresiones visuales o auditivas o representaciones que sugieran } \\
\text { a un menor que no adquirir o usar un producto puede generar } \\
\text { rechazo social o falta de aceptación en un grupo }\end{array}$ \\
\hline & $\begin{array}{l}\text { - La información o publicidad no debe afirmar ni insinuar que } \\
\text { el consumo de un alimento o bebida sustituye alguna de las tres } \\
\text { comidas principales del día }\end{array}$ \\
\hline & $\begin{array}{l}\text { - La información o publicidad no puede usar expresiones } \\
\text { cualitativas, diminutivos o adjetivos en el precio de un producto }\end{array}$ \\
\hline
\end{tabular}

Así mismo, el parágrafo del artículo 4 del Decreto 975, compilado en el artículo 2.2.2.33.4 del Decreto 1074 que consagra los deberes del anunciante respecto de la información y publicidad dirigida a menores, dispone que el medio de comunicación será responsable solidariamente de los perjuicios que cause la publicidad engañosa, solo si se comprueba dolo o culpa grave.

Respecto a la forma de separar los programas de la publicidad comercial, el artículo 5 del Decreto 975, compilado en el artículo 2.2.2.33.5 del Decreto 1074 habla de los anuncios publicitarios dirigidos a menores durante un programa de radio o televisión, consagrando lo siguiente:

"Art. 5. Anuncios publicitarios dirigidos a niños, niñas y adolescentes emitidos durante un programa de radio o televisión. En todos aquellos eventos en los que un anuncio publicitario dirigido exclusivamente a niños, niñas y adolescentes se incorpore en el contenido editorial de una producción nacional de radio o de televisión emitida durante la franja $u$ borario infantil o adolescente y cuyo público objetivo sean niños, niñas y adolescentes, deberá precisarse por parte del medio de comunicación, de forma expresa, que el anuncio no bace parte del contenido de dicho programa. Para estos efectos, toda publicidad que se incorpore en el contenido editorial deberá estar precedida de la leyenda "el presente es un anuncio publicitario que no hace parte del contenido de este programa", 
la cual deberá anunciarse de viva voz, así como en caracteres visibles en el caso de los programas emitidos en medios audiovisuales" 21 .

Abordando otras formas de información y publicidad dirigida a los menores de edad, el Decreto 975 se ocupa en su artículo 6 compilado en el artículo 2.2.2.33.6 del Decreto 1074, de la información en la comercialización de juguetes. Sin embargo, consideramos que este artículo se queda bastante corto en la regulación de un tema que es de alta sensibilidad y que tiene un amplísimo alcance que no se ve cubierto en forma integral en la regulación colombiana.

El artículo 6 se limita a establecer que "(...) Sin perjuicio de lo dispuesto en la Ley 1480 de 2011 y en el presente decreto, la información relacionada con los juguetes que se comercialicen u ofrezcan al público en Colombia, deberá cumplir con lo previsto de manera especial en el reglamento técnico sobre los requisitos sanitarios de los juguetes, sus componentes y accesorios, de conformidad con lo dispuesto en la Resolución 3388 de 2008 del Ministerio de la Protección Social o la que la sustituya, modifique o adicione"22.

Para entender el alcance del artículo anterior, tenemos que mirar el contenido de la Resolución 3388 de 2008 "por la cual se expide el reglamento técnico sobre los requisitos sanitarios de los juguetes, sus componentes y accesorios, que se comercialicen en el Territorio Nacional, y se dictan otras disposiciones".

La Resolución 3388 tal como lo indica su artículo 1, establece un reglamento técnico sobre requisitos sanitarios que deben cumplir los juguetes que se fabriquen, importen, exporten, almacenen y comercialicen en Colombia "con el fin de eliminar o prevenir adecuadamente un riesgo para la salud y la seguridad humana"23.

Esta resolución se ocupa de indicar aspectos técnicos que deben cumplir los juguetes respecto al cumplimiento de requisitos, condiciones de inflamabilidad, propiedades eléctricas, condiciones higiénicas entre otros aspectos; concentrándose básicamente en temas de seguridad

En cuanto a la información que deben contener los juguetes, el Anexo B de la resolución establece directrices para clasificar los juguetes por edades para que estos sean correspondientes con las diferentes etapas de desarrollo físico y mental de los niños, y mediante la correcta rotulación de los mismos

21 Ibíd. Decreto 975 de 2014. Artículo 5, compilado en el Artículo 2.2.2.33.5 del Decreto 1074 de 2015.

22 Ibíd. Decreto 975 de 2014. Artículo 6, compilado en el Artículo 2.2.2.33.6 del Decreto 1074 de 2015

23 República de Colombia. Ministerio de la Protección Social. Resolución 3388 (8, septiembre, 2008). Por la cual se expide el reglamento técnico sobre los requisitos sanitarios de los juguetes, sus componentes y accesorios que se comercialicen en el Territorio Nacional, y se dictan otras disposiciones. Artículo 1. 
se dé información a los consumidores para que puedan seleccionar juguetes apropiados y seguros para los niños según su edad.

Sin embargo, la Resolución 3388 no desarrolla temas relacionados con la publicidad o información dirigida a los niños en su calidad de consumidores, que pueda influir en sus decisiones de consumo, por lo que podríamos concluir que la regulación sobre estos temas queda solo cubierta por el articulado de la Ley 1480 y el Decreto 975 compilado en el Decreto 1074.

Siendo así, frente al tema de la información y publicidad relacionada con juguetes que se comercialicen u ofrezcan al público en Colombia, el artículo 6 del Decreto 975 compilado en el artículo 2.2.2.33.6 del Decreto 1074 no dispone nada que vaya más allá de lo establecido en la Ley 1480 y en el mismo decreto sobre información y publicidad de productos que se comercialicen en Colombia, y tan solo se limita a reiterar el deber de cumplimiento del reglamento técnico sobre requisitos sanitarios de los juguetes, plasmado en la Resolución 3388.

No vemos que el tema de la publicidad en la comercialización de juguetes sea abordado de forma específica en el Decreto 975 compilado en el Decreto 1074 , siendo este regulado en forma general por las disposiciones sobre publicidad de "productos", consagradas en el decreto, lo cual, a nuestra manera de ver, resulta insuficiente como lo reiteraremos más adelante.

En cuanto a la información y publicidad dirigida a menores en el entorno digital, el artículo 7 del Decreto 975 compilado en el artículo 2.2.2.33.7 del Decreto 1074 establece lo siguiente: "Artículo 7. Información y publicidad en el entorno digital. Sin perjuicio de lo previsto en la Ley 1480 de 2011, lo dispuesto en este decreto y demás normas aplicables, la publicidad y oferta de productos dirigidos exclusivamente a niños, niñas y adolescentes, o aquellos que sean publicitados u ofertados en entornos o plataformas cuyo público objetivo y exclusivo sean aquellos o que puedan ser adquiridos, descargados, o a los que se pueda tener acceso por internet o a través de dispositivos móviles, deben incluir advertencias claras sobre la necesidad de contar con la autorización de sus padres o representantes para realizar la transacción"24.

Como se desprende del texto del artículo, el decreto solo dispone, sin perjuicio de las demás normas aplicables, que se deben incluir "advertencias claras" sobre la necesidad de contar con la autorización de los padres o representantes para poder realizar una transacción relacionada con publicidad y oferta de productos dirigidos exclusivamente a menores, publicitados u ofertados en entornos o plataformas cuyo público exclusivo sean los menores, o

24 República de Colombia. Ministerio de Comercio, Industria y Turismo. Decreto 975 (28, mayo, 2014). Por el cual se reglamentan los casos, el contenido y la forma en que se debe presentar la información y la publicidad dirigida a los niños, niñas y adolescentes en su calidad de consumidores. Artículo 7, compilado en el artículo 2.2.2.33.7, Decreto 1074 (26, mayo, 2015), Ministerio de Comercio, Industria y Turismo. Por medio del cual se expide el Decreto Único Reglamentario del Sector Comercio, Industria y Turismo. 
que puedan ser adquiridos, descargados o accedidos por internet o a través de dispositivos móviles.

Respecto a las quejas relacionadas con los derechos de los menores consumidores, el artículo 8 del Decreto 975 compilado en el artículo 2.2.2.33.8 del Decreto 1074 establece que las autoridades competentes en materia de protección al consumidor, entre las cuales se encuentran la Superintendencia de Industria y Comercio y las alcaldías municipales, deben tramitar las mismas, en forma prevalente.

Para el tema de las sanciones por el incumplimiento a lo establecido en el Decreto 975 compilado en el capítulo 33 del Decreto 1074, el artículo 9 del Decreto 975 compilado en el artículo 2.2.2.33.9 del Decreto 1074 dispone que estas corresponden a las previstas en los artículos 61 y 62 de la Ley 1480. El artículo 61 hace referencia a las sanciones que puede imponer la Superintendencia de Industria y Comercio y el artículo 62 alude a las sanciones facultativas de los alcaldes en sus respectivas jurisdicciones.

Después de haber hecho un repaso general a los temas contemplados por el Decreto 975 compilado en el capítulo 33 del Decreto 1074, podemos concluir que este regula en forma muy general los casos, contenido y forma en que se debe presentar la información y la publicidad dirigida a los menores de edad en su calidad de consumidores, dando lineamientos sobre información y publicidad para "productos y servicios", sin entrar a regular en forma detallada algunos temas específicos que están directamente relacionados con el consumo de los menores tales como el tema de la publicidad para juguetes y para alimentación, entre otros.

Para los temas de información y publicidad sobre alimentación y juguetes, vemos como el decreto menciona estos dos sectores de forma muy superficial, cuando en su artículo 4, numeral 7, establece que el anunciante "no deberá afirmar ni insinuar que el consumo de un alimento o bebida sustituye alguna de las tres comidas principales del día (desayuno, almuerzo y cena), y cuando en su artículo 6 dispone que además de dar cumplimiento a la Ley 1480 y al Decreto 975, la información relacionada con juguetes que se comercialicen en Colombia deberá cumplir con lo dispuesto en la Resolución 3388 de 2008,-reglamento técnico sobre los requisitos sanitarios de los juguetes, sus componentes y accesorios- ${ }^{25}$.

Entendemos que cuando el decreto habla de productos y servicios, los temas particulares relacionados con los juguetes y la alimentación, entre otros, se entienden cubiertos en forma general por el decreto. Sin embargo, consideramos que estos temas específicos merecen una mayor atención y 
por ende una regulación más detallada, pues abarcan temas sensibles para la protección de los menores, que merecen de más amplia protección legal.

Como veremos más adelante, algunos de estos temas específicos, se encuentran cobijados en la autorregulación publicitaria colombiana, pero por la misma naturaleza de esta, dichas disposiciones no cuentan con la fuerza vinculante que tendrían si estuvieran contenidas en el Decreto 975 de 2014 compilado en el Capítulo 33 del Decreto 1074 de 2015.

En este sentido, consideramos que el Decreto 975 compilado en el capítulo 33 del Decreto 1074 es un paso importante hacia la regulación de la información y la publicidad dirigida a los menores, pero se requiere de un mayor desarrollo legal que cubra en forma más amplia y específica algunos temas de gran sensibilidad para los menores que no han sido mayormente desarrollados en este, como es el tema de la publicidad sobre juguetes, del que se ocupa en forma especial el presente escrito.

\subsubsection{Código Colombiano de Autorregulación Publicitaria-vigente hasta marzo de 2018}

En el año 2013, la Comisión Nacional de Autorregulación Publicitaria -CONARP-, expidió el Código Colombiano de Autorregulación Publicitaria (en adelante CCAP, para efectos de este escrito), correspondiente a una nueva versión del código de autorregulación expedido por primera vez en Colombia en el año de $1980^{[26]}$, y el cual se constituyó según palabras de la Unión Colombiana de Empresas Publicitarias - UCEP-, como "(...) una regulación ponderada, con principios y conductas universales de respeto a la veracidad de la información, la decencia, la honestidad y a los derechos del consumidor y de los competidores, sin limitar la creatividad en aquellos aspectos que trascienden lo objetivo de la comunicación de las características del producto o servicio. Conscientes de su existencia y efectividad, sus lineamientos constituyen una guía útil para quien hace publicidad, y para quien recibe la información que a través de esta se le suministra"27.

Este ejercicio de autorregulación fue producto de la interacción del Estado y del sector privado en aquellas materias que eran de interés común. A este respecto, traemos a colación las siguientes palabras de Ximena Tapias, presidente de CONARP, las cuales fungieron como parte de la presentación del CCAP:

"(...) La regulación, esa práctica consistente en someter a reglas y a controlar en virtud del poder del Estado, viene dando paso a la autorregulación que es la

26 Unión Colombiana de Empresas Publicitarias UCEP. (en línea). http://www.ucepcol.com. (citado en agosto de 2016).

27 Unión Colombiana de Empresas Publicitarias UCEP. (en línea). http://www.ucepcol. com/\#!codigoautorregulacion/c4fn (citado en mayo 2019). 
elección voluntaria, producto del desarrollo, la madurez y la responsabilidad, de limitaciones en el ejercicio de la libertad. Aunque por el momento se trata todavía de una actividad comercial regulada por el Estado, la publicidad colombiana ha querido ir más allá de las licencias legales para establecer normas de comportamiento que, si bien restringen aún más la libertad reglada, ofrecen garantías de respeto hacia los demás y hacia la actividad que desarrollan honrando valores que, como la verdad, la decencia y la honestidad se erigen en principios de defensa del consumidor, sujeto por excelencia de la comunicación ${ }^{\prime 28}$.

\section{En cuanto a las características del código, la UCEP las definió de la siguiente manera:}

"1. Mantiene los principios generales de todos los códigos de autorregulación, como son la veracidad, la decencia y la bonestidad. Adicional a ello, incluye como principios rectores de la actividad la buena fe y la responsabilidad social, mostrando así el compromiso de la industria publicitaria con el mejoramiento integral del país.

2. Hace extensiva la aplicación del Código a todo tipo de publicidad que se pretenda difundir, independientemente de su origen.

3. En relación con el respeto de los derechos a la imagen y a la intimidad, los de propiedad industrial, los derechos ambientales y los de protección al consumidor, el Código establece una protección más detallada, que debe ser tenida en cuenta por quienes intervienen en la preparación de los mensajes publicitarios.

4. El capítulo sobre publicidad comparativa profundiza en aspectos importantes tales como las pruebas de las afirmaciones, los requisitos que se deben cumplir para su difusión y el respeto a la leal competencia, siempre en beneficio del consumidor.

5. Se establecen en el Código mayores controles para los contenidos de la publicidad de algunas categorías de productos como son: mensajes con causas sociales, medicamentos y productos para la salud y publicidad de bebidas alcohólicas, tabacos y cigarrillos.

6. Una de las novedades que introduce el Código, es la de destinar un capítulo completo a la publicidad de alimentos y bebidas no alcobólicas, disposiciones que no existían en su anterior versión, en atención a la responsabilidad que asume la industria con la salud de las personas $y$, en general, con la promoción de bábitos de vida saludables.

7. Otra novedad es que dedica un capítulo completo a los mensajes comerciales dirigidos a niños, niñas y adolescentes, en primer lugar, con el fin de adecuar sus disposiciones a las de la Ley 1098 de 2006, por la cual se expidió el Código de la Infancia y la Adolescencia y, en segundo lugar,

28 Comisión Nacional de Autorregulación Publicitaria Colombia, CONARP. Código Colombiano de Autorregulación Publicitaria. (en línea) http://media.wix.com/ugd/3455e7_799d2f146 d164ab79a620ee0e95e3b5b.pdf (citado en mayo 2019), p. 9. 
como un acto de consciencia de la industria publicitaria de la necesidad de protección especial que deben tener los menores de edad por parte de toda la sociedad.

8. En relación con las nuevas tecnologías, el Código reserva uno de sus capítulos a la publicidad en medios digitales interactivos, atendiendo a la expansión creciente de medios y canales que se encuentran disponibles boy en día para llegar a los consumidores. Así las cosas, el sector publicitario colombiano se compromete igualmente a mantener una conducta ética y responsable a través de los medios digitales.

9. La nueva versión adiciona el número de integrantes de la Comisión en tres miembros, que serán elegidos por los representantes de las organizaciones adberentes y los suscriptores del mismo, entre expertos independientes reconocidos e idóneos dentro de su área de práctica, ya sea en la publicidad, el derecho, los medios de comunicación, la protección de los derechos de consumidores, entre otros, con el fin de dotar a la Comisión de un amplio campo de trabajo a la bora de proferir fallos o emitir conceptos.

10. Por último, se crea el Consejo de Revisión de Autorregulación Publicitaria, que será el encargado de los trámites de segunda instancia, compuesto por tres miembros Ad-Honorem, seleccionados de entre personas de reconocida independencia, trayectoria, representatividad e idoneidad en los asuntos propios de la industria publicitaria, los derechos de los consumidores y/o la libre y leal competencia, para cada caso particular ${ }^{\prime \prime 2}$

Vemos entonces como el CCAP incluyó varias novedades en relación con sus anteriores versiones, dentro de las cuales se encontraba la inclusión de un capítulo -el séptimo-, sobre Los mensajes comerciales y los niños, niñas y adolescentes, en respuesta a la necesidad de proteger en forma especial a este segmento de la población.

Sin embargo, el CAAP estuvo vigente hasta marzo de 2018. A este respecto, encontramos la siguiente información en la página web de la Unión Colombiana de Empresas Publicitarias -UCEP-:

"La Comisión Nacional de Autorregulación Publicitaria - CONARP, fundada por representantes de la Unión Colombiana de Empresas Publicitarias -UCEP, la Asociación Nacional de Anunciantes -ANDA y la International Advertising Association - IAA, fue desde 1980 hasta abril de 2018 la máxima entidad autorreguladora de la publicidad en Colombia, encargada de velar por el respeto de las normas señaladas en el Código de Autorregulación Publicitaria, a través de flexibles y eficaces mecanismos de respeto y vigilancia de las normas que rigen los contenidos de mensajes publicitarios emitidos a través de todos los medios

29 Unión Colombiana De Empresas Publicitarias. Características del nuevo Código Colombiano de Autorregulación Publicitaria. http://www.ucepcol.com/\#!codigoautorregulacion/c4fn (citado en mayo 2019). 
de comunicación en el país, lo cual la identificó como un mecanismo alterno de resolución de conflictos en materia publicitaria.

En agosto de 2017, la UCEP presentó ante las asociaciones miembro de la CONARP, una propuesta de reforma del sistema que puede conocerse aquí.

A partir de marzo de 2018, la ANDA y la ANDI determinaron adoptar un nuevo sistema de autorregulación de que la UCEP no forma parte y, en consecuencia, la CONARP y el código ético expedida por este, perdieron vigencia y aplicabilidad.

Para informes acerca del sistema de autorregulación futuro, dirigirse a la Asociación Nacional de Anunciantes -ANDA" ${ }^{\prime \prime 2}$.

Entonces, como lo mencionamos, el CCAP tuvo vigencia hasta marzo de 2018 para darle paso a un futuro sistema de autorregulación de la publicidad en Colombia el cual será definido por la ANDA, la ANDI y otras entidades. No obstante lo anterior, y mientras se conoce el nuevo sistema de autorregulación, utilizaremos al CCAP como referencia para efectos de hacer una comparación académica entre su capítulo séptimo -Los mensajes comerciales y los niños, niñas y adolescentes" y las normas de autorregulación españolas en lo referente a publicidad dirigida a menores de edad con respecto a juguetes.

Veamos entonces el capítulo séptimo del CCAP que contiene nueve artículos que van del 38 al 46, cuyos aspectos principales destacamos y resumimos a continuación ${ }^{31}$ :

Principios rectores-Artículo 38

- Mensaje comercial dirigido a menores de edad: aquel que promociona un producto/servicio para el que estos son los únicos o una parte sustancial de los consumidores, y se presenta de forma dirigida principalmente a estos

- Los mensajes comerciales dirigidos a menores de edad deben cumplir

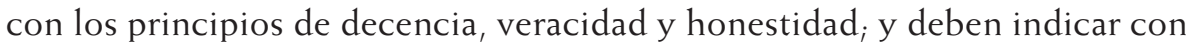
claridad, cuando algún contenido no es apropiado para los menores

- Para el código, son niños y niñas los comprendidos entre 0 y 12 años

Veracidad-Artículo 39

- La información de productos promocionados en mensajes comerciales dirigidos a menores de edad deberá ser veraz, clara, transparente suficiente,

30 Union Colombiana de Empresas Publicitarias UCEP https://www.ucepcol.com/conarp-cjce (citado en mayo 2019).

31 Comisión Nacional de Autorregulación Publicitaria Colombia, CONARP. Código Colombiano de Autorregulación Publicitaria. (en línea) http://media.wix.com/ugd/3455e7_799d2f146 d164ab79a620ee0e95e3b5b.pdf (citado en mayo 2019), pp. 26 y 27. 
y apropiada para su edad, motivaciones, intereses y condiciones de madurez, para no inducirlos a error sobre características, condiciones de uso/consumo del producto, y expectativas frente al producto

- Los mensajes comerciales informarán sobre la necesidad de adquisiciones adicionales (accesorios, etc.) requeridas para producir el resultado descrito en el mensaje

Respeto a condiciones de credulidad-Artículo 40

La publicidad dirigida a los menores de edad:

- deberá respetar los sentimientos de credulidad, confianza y lealtad de los menores de edad

- no podrá manipular sus emociones para crearles hábitos de consumo excesivo o compulsivo o desarrollar conductas que atenten contra su vida, su seguridad, su salud e integridad

Respeto a comportamientos y valores-Artículo 41

- Los mensajes comerciales dirigidos a menores de edad deberán respetar los comportamientos sociales aceptados, hábitos y estilos sanos de vida y las actitudes positivas

Prohibiciones especiales para niños y niñas-Artículo 42

Los mensajes comerciales dirigidos a niños/as no podrán:

- Usar expresiones que ordenen, constriñan o compelan a la adquisición, uso/consumo de productos, o usar o invitar a usar presiones para que padres/ adultos compren el producto para el niño/a

- Usar imágenes, textos, expresiones visuales o auditivas que involucren directa o indirectamente, juicios valorativos respecto de la acción u omisión relativa a la compra, posesión, uso, disfrute, o consumo de un producto

- Presentar niños/as en situaciones peligrosas, inseguras o que atenten contra su integridad, ni representar usos peligrosos de un producto o situaciones que puedan inducir a los niños/as a imitarlos o participar en actividades riesgosas

- Escenificar, mostrar o insinuar actos con contenido sexual, o de erotismo y seducción, o situaciones que inciten a la violencia, hagan apología de actos delictivos o animen a los niños/as a asociarse con extraños o entrar a lugares peligrosos o extraños

- Incentivar a los niños/as a adquirir productos u obtener beneficios a través de internet o teléfono, sin acompañamiento de un adulto responsable

- Incentivar el sobre consumo o la abstención del consumo balanceado de alimentos y bebidas

- Minimizar el grado de habilidad o edad requerida para ensamblar o usar un producto

- Demeritar la responsabilidad y autoridad de los padres 


\section{Prohibición general-Artículo 43}

No se podrá hacer alusión a la violencia, pornografía, discriminación, o consumo de drogas, alcohol, tabaco y derivados, en espacios para juegos/ servicios para menores de edad, ni en la programación dirigida a estos emitida por cualquier medio.

Publicidad exclusiva para adultos-Artículo 44

- La publicidad exclusiva para adultos es aquella que promociona productos/ servicios cuyo uso/consumo por parte de menores de edad está legalmente prohibido o que por su contenido no debe ser vista o escuchada por estos

- No puede ser exhibida en ningún medio, espacio u horario al cual puedan acceder libremente los menores de edad

- No pueden aparecer menores de edad ni siquiera acompañando a los adultos que aparecen en el mensaje

Precios-Artículo 45

Los precios indicados en la publicidad de productos dirigida a menores de edad, no podrá usar expresiones cualitativas, diminutivos o adjetivos tales como "barato", "regalado", "apenas" o "solo", entre otros.

Publicidad de alimentos-Artículo 46

La publicidad de alimentos y bebidas dirigida a menores de edad cuyo propósito sea promover hábitos de vida saludable, deberá:

- Fomentar un estilo de vida saludable y de calidad nutricional

- Alentar la higiene en la manipulación y el consumo

- Incluir mensajes preventivos con leyendas formativas, tales como "aliméntate balanceadamente", "realiza actividad física", "come frutas y verduras", entre otras

- Estos mensajes no deben engañar o exagerar sobre sus beneficios, ni atribuirles consecuencias sobre el estatus, superioridad o inferioridad, popularidad o aceptación social

De otra parte y aunque no pertenece al capítulo sobre mensajes comerciales dirigidos a menores de edad, es importante mencionar el Artículo 51 del CCAP sobre Los mensajes comerciales digitales $y$ los niños, niñas $y$ adolescentes, que en resumen estableció que se debe motivar a los padres/tutores a participar y/o supervisar las actividades interactivas de sus hijos menores y que solo puede divulgarse a terceros información personal de los menores autorizada por ley, que pueda ser identificada después de obtener el consentimiento del padre/ 
tutor. De igual forma, el artículo estableció que los sitios web dedicados a productos/servicios sujetos a restricciones (bebidas alcohólicas, por ejemplo), deben adoptar medidas para restringir el acceso de los menores.

Más adelante, haremos un estudio comparativo entre las disposiciones del CCAP, la normativa colombiana y las disposiciones del Código de Autorregulación Español de la Publicidad Infantil de Juguetes -CAPIJ-.

\subsection{ESPAÑA}

Frente al tema de la publicidad e información dirigida a los menores de edad consumidores, encontramos que España tiene una regulación que consideramos relevante, sobre todo en la medida en que ha presentado un desarrollo destacado en materia de autorregulación; razón por la cual, centraremos nuestro estudio comparativo en este país.

Dentro de la legislación española, encontramos la Ley 34/1988, de 11 de noviembre, -Ley General de Publicidad-, modificada por la Ley 29/2009, de 30 de diciembre, -Por la que se modifica el régimen legal de la competencia desleal y de la publicidad para la mejora de la protección de los consumidores y usuarios-; la cual establece que la publicidad se regirá por esa ley, por la Ley de Competencia Desleal y por las normas especiales que regulen determinadas actividades publicitarias.

El artículo 3 de la Ley 34/1988 establece aquello que es considerado como publicidad ilícita, y su literal b) hace referencia a la publicidad dirigida a menores de edad en los siguientes términos:

\section{"Artículo 3. Publicidad ilícita.}

Es ilícita: (...) b) La publicidad dirigida a menores que les incite a la compra de un bien o de un servicio, explotando su inexperiencia o credulidad, o en la que aparezcan persuadiendo de la compra a padres o tutores. No se podrá, sin un motivo justificado, presentar a los niños en situaciones peligrosas. No se deberá inducir a error sobre las características de los productos, ni sobre su seguridad, ni tampoco sobre la capacidad y aptitudes necesarias en el niño para utilizarlos sin producir daño para sí o a terceros. (... $)^{\prime \prime 32}$.

De igual forma, y en alusión al tema, encontramos la Directiva 2005/29/CE Del Parlamento Europeo y del Consejo, de 11 de mayo de 2005, sobre prácticas comerciales desleales, que en su Anexo I sobre "prácticas comerciales que se consideran desleales en cualquier circunstancia", establece en su numeral 28 como "práctica comercial agresiva" lo siguiente: "(...) 28. Incluir en una publicidad 
una exhortación directa a los niños para que compren o convenzan a sus padres $u$ otros adultos de que les compren los productos anunciados. (... $)^{33 "}$.

Las anteriores son solo algunas de las disposiciones sobre el tema de la información dirigida a los menores de edad consumidores tanto en la legislación española como en las directivas europeas; más sin embargo, hemos decidido centrar nuestro estudio en la autorregulación española, la cual, como veremos, es extensa y abarca varios temas relevantes relacionados con la publicidad dirigida al menor de edad consumidor, en especial con la publicidad sobre juguetes.

\subsubsection{Autorregulación española-Antecedentes}

En el año 1993 la Asociación Española de Fabricantes de Juguetes -AEFJ- junto con la Unión de Consumidores de España -UCE-, suscribieron un pacto de autorregulación conocido como el "Código Deontológico para Publicidad Infantil", el cual contenía seis principios y once directrices para la publicidad dirigida a los niños y niñas.

En cuanto a los principios del código, estos contenían afirmaciones y conceptos que en nuestra opinión se constituyen como el origen de la necesidad de establecer unas directrices a la publicidad dirigida a los menores de edad.

El siguiente es un resumen de los conceptos básicos recogidos en estos principios:

- Los niños más pequeños tienen capacidad limitada para evaluar la credibilidad de la información que reciben y los anunciantes deben actuar con la responsabilidad que implica esta circunstancia

- Los anunciantes deben tener en cuenta el nivel de comprensión de su público objetivo

- Se reconoce la naturaleza imitativa de los niños

- Se reconoce que la publicidad puede jugar un papel en la educación infantil

- Los anunciantes deben presentar información a los niños de forma sincera y precisa

- Los anunciantes deben capitalizar el potencial de la publicidad para influir en forma positiva en el comportamiento de los menores

33 Unión Europea. Directiva 2005/29/CE. Del Parlamento Europeo y del Consejo. (11, mayo, 2005). Relativa a las prácticas comerciales desleales de las empresas en sus relaciones con los consumidores en el mercado interior, que modifica la Directiva 84/450/CEE del Consejo, las Directivas 97/7/CE, 98/27/CE y 2002/65/CE del Parlamento Europeo y del Consejo y el Reglamento (CE) no. 2006/2004 del Parlamento Europeo y del Consejo. Anexo 1, numeral 28 . 
- Los anunciantes deben extremar sus cuidados para no inducir a error a los menores. Los anuncios no deben crear expectativas poco razonables sobre la calidad o prestaciones de un producto

- Los anunciantes no deben explotar o aprovecharse de la capacidad imaginativa de los niños

- Los anunciantes deben contribuir a desarrollar relaciones padre-hijo constructivas $^{34}$

Los anteriores conceptos y afirmaciones tienen en común el reconocimiento de que los menores son vulnerables e influenciables frente a la publicidad, razón por la cual esta debe respetar unas directrices tendientes a su protección.

En cuanto a las directrices recogidas en el código, estas abarcan los siguientes once temas respectivamente:

1. Presentación de los productos y reclamaciones

2. Identificación de la publicidad

3. Previsión de ventas

4. Información y rectificaciones

5. Presentaciones comparativas

6. Apoyo y promoción a través de personajes de programas y personajes del mundo editorial

7. Premios, promociones, concursos

8. Premios

9. Clubes infantiles

10. Concursos

11. Seguridad ${ }^{35}$

Este pacto de autorregulación español fue objeto de dos revisiones motivadas por la necesidad de actualizarlo frente a los cambios "tecnológicos, comunicativos y socioculturales que han tenido repercusiones legales y normativas sobre la publicidad y promoción de juguetes $(\ldots)^{136}$.

La primera revisión del pacto fue en el año 2010, cuando el nombre del código fue cambiado de "Código Deontológico para la Publicidad Infantil" a "Código de Autorregulación de la Publicidad Infantil de Juguetes", pasando

34 Asociación Española de Fabricantes de Juguetes (AEFJ) y Unión de Consumidores de España (UCE). Código Deontológico para Publicidad Infantil de 14 de diciembre de 1993. (en línea). http://docplayer.es/3855230-Codigo-deontologico-para-publicidad-infantil.html (citado en mayo 2019).

35 Ibíd.

36 Asociación Española de Fabricantes de Juguetes. Código de Autorregulación de la Publicidad Infantil de Juguetes (en línea). https://www.aefj.es/contenidos/codigo-de-autorregulacionde-la-publicidad-infantil-de-juguetes (citado en mayo 2019). 
de autorregular la publicidad infantil en términos generales, a autorregular la publicidad infantil de juguetes en forma específica.

La segunda revisión fue en el año 2015, siendo esta la que procederemos a estudiar a continuación, haciendo un paralelo con la regulación colombiana.

Aunque esta autorregulación española sobre publicidad dirigida a menores es específica para el tema de los juguetes y la regulación colombiana es general para "productos y servicios", consideramos que ambas son comparables dado que los temas que abarcan son muy similares y a que dentro de la regulación colombiana el tema de los juguetes queda subsumido dentro de la regulación de productos.

2.2.1.2 Código de Autorregulación de la Publicidad Infantil de Juguetes -CAPIJ-

El "Código de Autorregulación de la Publicidad Infantil de Juguetes" (en adelante, CAPIJ) es el código sectorial promovido por la Asociación Española de Fabricantes de Juguetes, cuya última versión fue suscrita en diciembre de 2015 con entrada en vigor el 1 de enero de 2016, actualizando así los códigos de autorregulación precedentes de los años 1993 y 2010. En la introducción del CAPIJ se desataca que éste hace parte de una estrategia de protección al menor, puesta en marcha desde 1993 por la Asociación Española de Fabricantes de Juguetes, cuyo objetivo es "promover el derecho a la comunicación comercial y a la libre competencia de las empresas jugueteras, salvaguardando los intereses de la infancia" ${ }^{137}$.

Así mismo, en su introducción el CAPIJ parte de la base de que los menores de edad tienen derecho a ser informados sobre los productos que les interesan, pero que su capacidad de evaluar la información que reciben es limitada, razón por la cual los padres, educadores y medios de comunicación, entre otros, deben impulsar el desarrollo de la comprensión de los mensajes y fomentar la publicidad responsable ${ }^{38}$.

En cuanto a su objetivo, el CAPIJ establece que consiste en "establecer un conjunto de reglas que guiarán a las compañías jugueteras asociadas en el desarrollo, ejecución y difusión de sus mensajes publicitarios dirigidos a menores. CAPIJ está en línea con los Principios del Código de la International Chamber of Comerce, Compendium of ICC rules on children and young people and marketing, de 01/04/2003 del Código TIE, European Code for Advertising Toys to children y del de ICTI, Guiding principles for advertising and marketing communication to children" ${ }^{\prime \prime 39}$. 
En la introducción también se establece el alcance de las normas del CAPIJ, al indicar que las mismas precisan y amplían el alcance de las obligaciones legales exigibles a la publicidad y promoción de juguetes dirigida a menores, en beneficio del interés general, de los consumidores y del mercado; y que las empresas adherentes a este respetarán la legislación general en materia de publicidad y las normas sobre protección a los menores de edad, al igual que las normas contenidas en el código en cuanto a la publicidad y promoción de juguetes dirigida a menores ${ }^{40}$.

Respecto a su ámbito de aplicación, este es la publicidad infantil de juguetes. El CAPIJ define publicidad como "toda forma de comunicación realizada por una persona física o jurídica, pública o privada en el ejercicio de una actividad comercial, industrial, artesanal o profesional, con el fin de promover de forma directa o indirecta la contratación de bienes muebles o inmuebles, servicios, derechos y obligaciones" ${ }^{\prime 4}$; y define publicidad infantil como "aquella que se dirige o alcanza un público compuesto fundamentalmente por menores de 15 años" ${ }^{\prime \prime 2}$. Sin embargo, dentro de los menores de 15 años, el CAPIJ considera que la etapa de 0 a 7 años merece especial atención y una aplicación más estricta del código.

En cuanto a la regulación del CAPIJ, está se encuentra recogida en el título denominado "normas éticas", el cual contiene y desarrolla los siguientes temas:

1. Principio de legalidad

2. Principio de lealtad

3. Presentación de los productos

4. Información sobre los productos

5. Presión de ventas

6. Apoyo y promoción a través de personajes y programas

7. Identificación de la publicidad

8. Presentaciones comparativas

9. Promociones, sorteos, concursos y clubes infantiles

10. Seguridad

11. Educación y valores cívicos

12. Protección de datos

13. Publicidad de juguetes por internet, nuevas tecnologías y nuevas formas publicitarias

40 Ibíd.

41 Ibíd.

42 Ibíd. 


\subsection{ESTUDIO COMPARATIVO ENTRE LAS NORMAS DEL CAPIJ Y LA NORMATIVIDAD COLOMBIANA-ENFOQUE SOBRE LA PUBLICIDAD PARA JUGUETES}

A continuación, haremos una exposición de las normas éticas contenidas en el CAPIJ y haremos una comparación de estas con las normas colombianas contenidas en la Ley 1480 de 2011, el Decreto 975 de 2014 compilado en el capítulo 33 del Decreto 1074 de 2015 del Ministerio de Comercio Industria y Turismo "Por medio del cual se expide el Decreto Único Reglamentario del Sector Comercio, Industria y Turismo" y el "Código Colombiano de Autorregulación Publicitaria"-CCAP, recordando la salvedad hecha en lo referente a que el CCAP estuvo vigente hasta marzo de 2018, y será reemplazado por un nuevo sistema de autorregulación. Sin embargo, en el entretanto y con propósitos meramente académicos, miraremos las normas del CCAP para efectos de hacer la comparación normativa.

Tal como lo mencionamos anteriormente, aunque el CAPIJ regula en forma específica la publicidad de juguetes y las normas colombianas regulan en forma general los productos y servicios, consideramos que ambas regulaciones son comparables en atención a los temas que abarcan los cuales son muy similares, y a que el sector de los juguetes queda subsumido en la regulación de productos que hace la normativa colombiana.

\section{$\underline{\text { Principios rectores }}$}

El CAPIJ consagra los principios de legalidad y lealtad en los numerales primero y segundo de su título sobre "normas éticas". Estos principios establecen en términos generales, que la publicidad infantil de juguetes se ajustará a la legislación vigente, deberá ser decente, honesta y veraz y se ajustará a la buena fe y a los buenos usos mercantiles.

Si comparamos los principios consagrados en el CAPIJ con lo consagrado en el CCAP, encontramos que el CCAP contiene los principios de decencia, veracidad y honestidad como rectores de los mensajes comerciales dirigidos a niños/as y adolescentes; coincidiendo ambos códigos en la consagración de estos principios.

Sin embargo, y aunque no los incluye expresamente en el capítulo de mensajes comerciales dirigidos a menores de edad, el CCAP se extiende a otros principios en su capítulo segundo "De los principios generales y su desarrollo normativo", cuando consagra en su artículo 8 sobre principios básicos, que "sin perjuicio del sometimiento al ordenamiento Constitucional y Legal exigible por las autoridades competentes, los mensajes comerciales se rigen por los principios de Veracidad, DeCEnCIA, Honestidad, BuEnA FE 
y RESPONSABILIDAD SOCIAL $(\ldots)^{\prime \prime 4}$; con lo que se puede concluir que ambos códigos de autorregulación, tanto el español como el colombiano vigente hasta marzo de 2018, contienen los mismos principios rectores, incluyendo el CCAP como novedad frente al CAPIJ, el principio de responsabilidad social.

\section{Presentación de los productos}

El numeral tercero del CAPIJ sobre "Presentación de los productos" se refiere, en términos generales a que la publicidad de juguetes dirigida a los menores no debe inducir a error sobre las características del producto.

El siguiente es un resumen de los puntos más relevantes del CAPIJ para el tema de la presentación de productos en la publicidad de juguetes dirigida a menores de edad:

- No se debe inducir a error sobre las características o prestaciones del producto

- No se debe confundir a los menores sobre los beneficios derivados del uso del producto (por ejemplo, adquisición de fortaleza, popularidad, etc.)

- Se debe evitar generar falsas expectativas en los menores y se debe reflejar en forma veraz las prestaciones reales del producto

- Se deben evitar las presentaciones que puedan asustar a los niños, la violencia gratuita y las presentaciones agresivas

- Los juguetes que requieran de un montaje deberán indicarlo. Los productos deben presentarse con una referencia clara y directa a su tamaño real ${ }^{44}$

El objetivo general del numeral tercero del CAPIJ respecto al deber de no inducir a error a los menores sobre las características de los productos, se encuentra recogido en la legislación colombiana cuando la Ley 1480 en su artículo 3 numeral 1.4 establece el derecho de los consumidores a ser protegidos contra la publicidad engañosa, y cuando el artículo 2.2.2.33.3 del Decreto 1074 de 2015 establece que las comunicaciones que busquen influir las decisiones de consumo de los menores no pueden inducir a error, engaño o confusión.

Así mismo, lo establecido en el CAPIJ en relación con que los anuncios de juguetes deben evitar presentaciones que asusten a los niños o con violencia gratuita o presentaciones agresivas, se encuentra recogido en el artículo 2.2.2.33.3 del Decreto 1074 que establece que los anuncios dirigidos a

43 Comisión Nacional de Autorregulación Publicitaria Colombia, CONARP. Código Colombiano de Autorregulación Publicitaria. (en línea) http://media.wix.com/ugd/3455e7_799d2f146 d164ab79a620ee0e95e3b5b.pdf (citado en mayo 2019).

44 Asociación Española de Fabricantes de Juguetes. Código de Autorregulación de la Publicidad Infantil de Juguetes. (en línea). https:/www.aefj.es/contenidos/codigo-de-autorregulacionde-la-publicidad-infantil-de-juguetes (citado en mayo 2019). 
menores no deben contener ninguna forma de violencia, discriminación, acoso, y en general, cualquier conducta que pueda afectar la integridad física de una persona.

El artículo 2.2.2.33.4 del Decreto 1074 también recoge aspectos contenidos en el numeral 3 del CAPIJ, cuando establece que el anunciante debe evitar el uso de imágenes, textos, expresiones o representaciones que no correspondan con la realidad del producto en lo relacionado con su funcionamiento o características, y cuando prohíbe exagerar el verdadero tamaño, naturaleza, durabilidad y uso del producto, y usar imágenes, textos, expresiones o representaciones que sugieran al menor que no adquirir o usar un producto puede generar efectos como el rechazo social o falta de aceptación en un grupo.

En cuanto al CCAP, al comparar sus disposiciones sobre presentación de productos con las disposiciones del CAPIJ sobre el mismo tema, encontramos que ambos códigos recogen y comparten el criterio respecto a que la publicidad dirigida a menores no deberá inducirlos a error sobre las características del producto, sus prestaciones y las expectativas del menor frente al producto (ver art. 39 del CCAP); y aunque no hay una coincidencia total entre ambos temas, se podría interpretar que el CCAP recoge en su artículo 41 un punto que podría coincidir con lo establecido en el CAPIJ relativo a que los anuncios de juguetes deberán evitar presentaciones que puedan asustar a los niños y evitar la violencia gratuita y las presentaciones agresivas, cuando el CCAP dispone que los mensajes comerciales dirigidos a menores deben respetar los comportamientos socialmente aceptados y actitudes positivas.

\section{Información de los productos}

Para el tema de información de productos consagrado en el numeral 4 del CAPIJ, uno de los aspectos que consideramos más relevantes es el referente a que los anuncios infantiles de juguetes deben establecer claramente lo que se incluye y lo que se excluye en el producto, como por ejemplo si se incluyen las pilas. Entre otros temas, el numeral también hace alusión a que la presentación y uso del producto debe demostrarse de forma en que pueda ser repetido por el niño/a y que cualquier información adicional en un anuncio de juguetes deberá expresarse en un lenguaje comprensible para los menores y de forma clara, legible y destacada.

El Decreto 1074 de 2015 toca algunos de los aspectos mencionados en el numeral 4 del CAPIJ sobre "Información de los Productos", cuando prohíbe no informar que las baterías o accesorios que se muestran en el anuncio no están incluidos con el producto o que se venden por separado o no informar que para el funcionamiento de un producto se requiere de baterías o algún elemento complementario (artículo 2.2.2.33.4, numeral 2, literales 2.3 y 2.4).

El CCAP también aborda algunos de estos temas cuando en su artículo 39 establece que los mensajes deben informar si se requiere hacer adquisiciones 
adicionales para producir el resultado descrito en el mensaje ${ }_{i}$ y cuando en su art. 42, numeral 7 establece que los mensajes comerciales no podrán minimizar el grado de habilidad o de edad requerida para ensamblar o utilizar un producto y "(...) cuando la publicidad muestra resultados de un dibujo, construcción, artesanal o modelo armado de juguete o kit, los resultados deben ser razonablemente alcanzables por un niño o niña promedio" ${ }^{\prime 4}$.

\section{Presión de ventas}

El numeral 5 del CAPIJ sobre "Presión de ventas" señala varios aspectos en los que no debe incurrir la publicidad de juguetes dirigida a menores, dentro de los cuales resaltamos en forma resumida los siguientes:

La publicidad infantil de juguetes no debe:

- Llamar directamente a los menores para que compren el producto anunciado, incitarles a que sus padres u otros adultos lo compren, ni sugerir que un padre/adulto que compra un producto es un mejor padre/adulto que el que no lo compra

- Apremiar a los menores a la obtención del producto

- Dar la impresión de que adquirir un producto dará una mayor aceptación al niño entre sus amigos, o el no adquirirlo provocará su rechazo

- Sugerir que la compra y uso de un producto dará a su usuario prestigio, habilidades y otras cualidades de los personajes que aparecen en el anuncio

- Usar en el precio del producto reduccionismos como "solo" o "nada más"46

Si observamos, el Decreto 1074 de 2015 recoge en forma parcial el contenido del numeral 5 del CAPIJ, cuando en su artículo 2.2.2.33.4, numeral 6 dispone que la publicidad no debe sugerir al menor que no adquirir o usar un producto puede generar rechazo social por parte de un grupo, y cuando en su numeral 8 establece que la publicidad no podrá usar expresiones cualitativas, diminutivos o adjetivos respecto al precio del producto.

Los otros aspectos regulados por el numeral 5 del CAPIJ, tales como la incitación a los menores para que pidan a los adultos que les compren productos/servicios, apremiar a los menores para comprar un producto, sugerir que el adulto que compra un producto/servicio es mejor que los que no lo hacen, y sugerir que un producto/servicio dará a quien lo use las habilidades

45 Comisión Nacional de Autorregulación Publicitaria Colombia, CONARP. Código Colombiano de Autorregulación Publicitaria. (en línea) http://media.wix.com/ugd/3455e7_799d2f146 d164ab79a620ee0e95e3b5b.pdf (citado en mayo 2019).

46 Asociación Española de Fabricantes de Juguetes. Código de Autorregulación de la Publicidad Infantil de Juguetes. (en línea). https://www.aefj.es/contenidos/codigo-de-autorregulacionde-la-publicidad-infantil-de-juguetes (citado en mayo 2019). 
o cualidades de los personajes que aparecen en el anuncio, no son abordados por la legislación colombiana.

En cuanto al código de autorregulación colombiano, este aborda varios temas regulados por el numeral 5 del CAPI, tales como que no se debe llamar directamente a los menores a comprar un producto, incitarles a que sus padres o adultos lo compren, sugerir que un padre que compra un producto es mejor que el que no lo compra, ni apremiar a los menores a la obtención de un producto. A este respecto, el art. 42, numeral 1 del CCAP dispone que los mensajes comerciales dirigidos a menores no podrán usar expresiones imperativas que ordenen, constriñan o compelan a la adquisición/uso/consumo de productos o usar o invitar a usar presiones a los padres/adultos para que compren el producto a los niños/as, siendo entonces ambas disposiciones similares.

De igual forma, encontramos similitudes en ambos códigos cuando el CAPIJ establece que la publicidad infantil de juguetes no debe dar la impresión de que adquirir un producto implicará la aceptación del niño entre sus amigos o la no compra su rechazo; y cuando el CCAP dispone en su artículo 42 numeral 2 , que los mensajes no podrán usar imágenes, textos o expresiones que involucren juicios valorativos respecto de la acción u omisión relativa a la compra, posesión, uso, disfrute o consumo de un producto.

En cuanto a los precios de un producto, el CAPIJ dispone que no se podrán usar reduccionismos, tales como "solo" o "nada más"; y en el mismo sentido, el CCAP establece en su artículo 45 que en los precios no se podrán usar expresiones cualitativas, diminutivos o adjetivos, tales como "solo", "barato" o regalado", entre otras.

\section{Apoyo y promoción a través de personajes y programas}

El numeral 6 del CAPIJ sobre "Apoyo y promoción a través de personajes y programas" establece en términos generales que la publicidad de juguetes dirigida a menores no debe explotar la confianza de estos en sus padres u otras personas o personajes, por lo que en la publicidad no podrán participar ni aparecer personajes populares entre los niños, para evitar influenciarlos indebidamente al comprar un producto promocionado por personajes. La anterior prohibición está acompañada de algunas excepciones que son listadas en el mismo numeral.

El tema de apoyo y promoción a través de personajes y programas no es abordado en forma directa por la legislación colombiana en materia de publicidad dirigida a menores de edad. Sin embargo, el CCAP lo aborda, -aunque no en relación con el apoyo y promoción a través de personajes como lo hace el CAPIJ-, cuando en su artículo 40 establece que la publicidad dirigida a los menores deberá respetar los sentimientos de credulidad, confianza y lealtad de estos. 


\section{Identificación de la publicidad}

El numeral 7 del CAPIJ sobre "Identificación de la publicidad" establece que los anuncios de juguetes dirigidos a menores deben separarse en forma clara de los programas, para efectos de no confundir al menor sobre la naturaleza comercial de la publicidad.

Este tema es abordado por el Decreto 1074 de 2015, cuando en su artículo 2.2.2.33.5 dispone que cuando un anuncio publicitario dirigido a menores se incorpore en el contenido editorial de una producción nacional de radio o televisión cuyo público objetivo sean los menores, el medio de comunicación debe precisar que el anuncio no hace parte del contenido del programa.

\section{Presentaciones comparativas}

El numeral 8 del CAPIJ sobre "Presentaciones comparativas" establece que la publicidad que compara un producto anunciado con otro debe proporcionar información real y debe ser demostrada con justificaciones válidas y adecuadas para efectos de que los menores la puedan comprender con claridad. Este punto sobre publicidad comparativa no es abordado por el Decreto 1074 de 2015. En cuanto al CCAP, aunque este no lo aborda en el capítulo sobre publicidad dirigida a menores de edad, si lo hace en forma completa en el capítulo cuarto sobre "Publicidad Comparativa".

\section{Promociones, sorteos, concursos y clubes infantiles}

El numeral 9 del CAPIJ sobre "Promociones, sorteos, concursos y clubes infantiles" establece algunas directrices para la publicidad de juguetes dirigida a menores donde se involucran promociones, sorteos, concursos y clubes infantiles.

Para entender con mayor claridad la justificación de este punto, nos remitimos a la directriz séptima del Código Deontológico de la Publicidad Infantil de 1993 que establecía que "(...) el uso de premios, promociones o concursos en publicidad tiene la capacidad de aumentar el atractivo de un producto ante el niño/a. Por ello, hay que prestar especial atención a la publicidad de estas técnicas de marketing, para proteger a los niños/as ante la explotación de su inmadurez $z^{\prime \prime 4}$.

La normativa colombiana no aborda el tema referente a la publicidad dirigida a menores cuando esta contenga referencias a premios, sorteos, promociones, concursos y clubes infantiles.

47 Asociación Española de Fabricantes de Juguetes y Unión de Consumidores de España. Código Deontológico para Publicidad Infantil. (en línea). http://docplayer.es/3855230Codigo-deontologico-para-publicidad-infantil.html (citado en mayo 2019), p. 7. 


\section{Seguridad}

El tema de la "Seguridad" es abordado en el numeral 10 del CAPIJ, cuyos puntos más relevantes resumimos de la siguiente manera:

Los anuncios para productos infantiles:

- Deben mostrar a los menores que estos deben usar productos adecuados para su edad

- Deben incluir adultos supervisando a los niños/as cuando los productos/ actividades lo requieran

- No deben presentar adultos o niños en situaciones inseguras o en actos perjudiciales para sí mismos o para otros

- Deben evitar escenas, imágenes o mensajes que alienten el uso peligroso o inadecuado de los productos

- Deben incluir adultos acompañando a los niños/as en lugares públicos cuando los productos/actividades puedan poner en peligro su seguridad

- No deben incitar a los niños a entrar a lugares extraños o a conversar con desconocidos ${ }^{48}$

El Decreto 1074 de 2015 no contiene disposiciones similares a las tratadas en el numeral 10 del CAPIJ. Sin embargo, el CCAP aborda la mayoría de estos temas cuando en su artículo 42, numerales 3 y 4 , establece que los mensajes comerciales no deberán presentar niños/as en situaciones peligrosas o que atenten contra su integridad, o que representen usos peligrosos de un producto o situaciones que puedan inducirlos a actividades riesgosas o animar a los niños/as a asociarse con extraños o a entrar a lugares peligrosos o extraños.

\section{Educación y valores cívicos}

El numeral 11 del CAPIJ trata sobre "Educación y valores cívicos" al establecer que la publicidad infantil de juguetes no presentará escenas sexuales inapropiadas, ni lenguaje obsceno, ni escenas sobre conductas adictivas ni que fomenten la discriminación por cualquier motivo; y evitará mostrar sesgos de género en la presentación que hacen de niños y niñas. De igual forma, establece que los anuncios evitaran utilizar en forma particular y directa el cuerpo de las mujeres o de los hombres en forma desvinculada al producto promocionado ${ }^{49}$.

El Decreto 1074 regula en términos generales los temas contenidos en el numeral 11 del CAPIJ, cuando en su artículo 2.2.2.33.4, numeral 4 establece que

48 Asociación Española de Fabricantes de Juguetes. Código de Autorregulación de la Publicidad Infantil de Juguetes. (en línea). https://www.aefj.es/contenidos/codigo-de-autorregulacionde-la-publicidad-infantil-de-juguetes (citado en mayo 2019).

49 Ibíd. 
la publicidad dirigida a menores no debe contener imágenes o información de contenido sexual, violento, discriminatorio o que promueva conductas contrarias a la moral y a las buenas costumbres.

De igual forma, el CCAP aborda algunos de los temas consagrados en el CAPIJ, cuando en su artículo 42 numeral 4 establece que en los mensajes comerciales no podrán escenificarse, mostrarse o insinuarse la realización de actos con contenido sexual, ni situaciones que inciten a la violencia o hagan apología de actos delictivos; y cuando en su Art. 43 prohíbe la alusión a la violencia, pornografía, discriminación, o consumo de drogas, alcohol o tabaco.

\section{Protección de datos}

El numeral 12 sobre "Protección de Datos" dispone en términos generales que las empresas que adhieran al CAPIJ se comprometen a cumplir con la legislación sobre protección de datos de carácter personal, al igual que prohíbe el tratamiento de datos de menores de 14 años sin el consentimiento de padres o tutores, permite el tratamiento de datos de los mayores de 14 con su consentimiento y prohíbe recabar datos del menor que permitan obtener información sobre los demás miembros del grupo familiar o las características del mismo, salvo los datos de identidad de los padres o tutores para efectos de obtener la autorización de estos mencionada en la norma ${ }^{50}$. Este tema sobre protección de datos de los menores no es regulado por el Decreto 1074.

\section{Publicidad de juguetes por internet, nuevas tecnologías y nuevas formas publicitarias}

El numeral 13 del CAPIJ sobre "Publicidad de juguetes por internet, nuevas tecnologías y nuevas formas publicitarias" trata en forma extensa diversos temas relativos a la publicidad de juguetes dirigida a menores a través de nuevas tecnologías como internet y nuevas formas publicitarias tales como el advergaming e infotainment. En principio, el numeral 13 establece que los anuncios en medios no convencionales como el internet, y las nuevas formas publicitarias estarán regulados por los principios de la publicidad en general, hasta que la comisión de seguimiento del código adopte obligaciones concretas derivadas de estas nuevas tecnologías, sobre todo en relación con la prestación e información de los productos.

Sin embargo, mientras se dictan estas nuevas reglamentaciones, el código establece que los anunciantes deben tener especial cautela en la publicidad dirigida a menores de 15 años por estos nuevos medios para efectos de que no se les induzca a error sobre las características y prestaciones del producto; 
al igual que establece que no se deberá incitar al menor a la compra del producto y los anuncios deberán presentarse en forma objetiva, sin estereotipos ni violencia.

El numeral 13 del CAPIJ es bastante extenso y abarca diversas materias que tratan, -entre otros asuntos-, temas sobre la obtención de información de los menores en línea, publicidad enviada a estos en línea, identificación y separación de contenidos dirigidos únicamente a adultos, protección de los menores en línea, envío de publicidad a los menores por correo electrónico, ofertas en línea y publicidad dirigida a menores en redes sociales, entre otros.

Si comparamos la regulación del tema de publicidad dirigida a menores en medios digitales consagrada en el CAPIJ, con la regulación para este tema dentro del Decreto 1074 de 2015, vemos que el decreto solo se enfoca en el hecho de que debe advertirse al menor sobre la necesidad de solicitar autorización a sus padres para la realización de llamadas o envío de mensajes de texto o multimedia que supongan un costo y que se requieran para adquirir un bien o servicio; y en que debe advertirse al menor sobre la necesidad de contar con la autorización de sus padres para realizar transacciones de productos publicitados a través de dispositivos móviles, internet o en el entorno digital en general.

Es así como el numeral 3 del artículo 2.2.2.33.4 del Decreto 1074 establece que "En todos los eventos en los que se informe o anuncie un bien o servicio para cuya adquisición se deban realizar llamadas o enviar mensajes de tex to o multimedia que supongan un costo para el consumidor, deberá informarse expresamente su valor y advertir al niño, niña y/o adolescente, que previo a realizar la llamada o enviar el mensaje, debe solicitar autorización de sus padres" ${ }^{\prime \prime 1}$.

Así mismo, el artículo 2.2.2.33.7 del Decreto 1074 sobre "información y publicidad en el entorno digital" establece lo siguiente: "Sin perjuicio de lo previsto en la Ley 1480 de 2011, lo dispuesto en este capítulo y demás normas aplicables, la publicidad $y$ oferta de productos dirigidos exclusivamente a niños, niñas y adolescentes, o aquellos que sean publicitados y ofertados en entornos o plataformas cuyo público objetivo y exclusivo sean aquellos o que puedan ser adquiridos, descargados, o a los que se pueda tener acceso por internet o a través de dispositivos móviles, deben incluir advertencias claras sobre la necesidad de contar con la autorización de sus padres o representantes para realizar la transacción" ${ }^{\prime 52}$.

En cuanto al tema de la publicidad por internet y nuevas tecnologías, el CCAP establece en su artículo 42, numeral 5, que los mensajes comerciales no podrán incentivar a los niños/as a adquirir productos a través de internet o por teléfono sin acompañamiento de un adulto; y establece en su artículo 51 sobre mensajes comerciales digitales dirigidos a menores de edad que se

51 República De Colombia. Ministerio de Comercio, Industria y Turismo. Decreto 1074 (26, mayo, 2015).Por medio del cual se expide el Decreto Único Reglamentario del Sector Comercio, Industria y Turismo. Artículo 2.2.2.33.4, numeral 3.

52 Ibíd. Artículo 2.2.2.33.7. 
debe motivar a los padres a participar y supervisar las actividades interactivas de sus hijos, que solo puede divulgarse a terceros información de los menores autorizada por ley y que los sitios web de productos o servicios sujetos a restricciones deben adoptar medidas para restringir el acceso a los menores.

De otra parte, el CCAP, al igual que el CAPIJ, hace mención al tema de la publicidad dirigida exclusivamente para adultos. En el CAPIJ se establece la necesidad de diferenciar la publicidad infantil de los contenidos dirigidos únicamente a adultos, mientras que el CCAP establece que la publicidad exclusiva para adultos no puede exhibirse en medios ni horarios a los que puedan acceder libremente los menores y en los mensajes exclusivos para adultos no pueden aparecer menores.

\subsection{CONCLUSIONES DEL ESTUDIO COMPARATIVO ENTRE LAS NORMAS DEL CAPIJ Y LA NORMATIVIDAD COLOMBIANA. ENFOQUE SOBRE LA PUBLICIDAD PARA JUGUETES}

Del anterior estudio comparativo entre las normas colombianas y el CAPIJ, en cuanto a la información y la publicidad dirigida a los menores de edad consumidores haciendo énfasis en la publicidad para juguetes, podemos llegar a las siguientes conclusiones:

- El Decreto 975 de 2014 compilado en el capítulo 33 del Decreto 1074 de 2015, al reglamentar los casos, el contenido y la forma en que se debe presentar la información y la publicidad dirigida a los niños, niñas y adolescentes en su calidad de consumidores, consagra temas importantes dentro de los cuales se encuentran los derechos de los menores frente a la información y la publicidad, los deberes de los anunciantes respecto a la información y publicidad dirigida a los menores, los anuncios publicitarios dirigidos a estos, la información en la comercialización de juguetes y la información en el entorno digital, entre otros.

- Así mismo, Colombia ha hecho esfuerzos autorregulatorios en materia de publicidad dirigida a menores de edad, los cuales fueron plasmados en el "Código Colombiano de Autorregulación Publicitaria"-CCAP, que, aunque estuvo vigente hasta marzo de 2018 , fue utilizado en este estudio a título de referencia mientras se expide un nuevo sistema de autorregulación.

- El Código Colombiano de Autorregulación Publicitaria contenía varios de los temas consagrados en el capítulo 33 del Decreto 1074, tales como los requisitos que debe cumplir la información a ser presentada a los menores de edad, forma en que se debe presentar la información, prohibiciones en la publicidad dirigida a menores, y precio, entre otros temas.

- Sin embargo, vemos como el Código de Autorregulación incluyó algunos temas que no son consagrados en el capítulo 33 del Decreto 1074, dentro de los cuales encontramos temas sobre el respeto a las condiciones de credulidad 
de los menores, publicidad exclusiva para adultos y publicidad de alimentos, entre otros.

- Al hacer un estudio de la regulación española sobre la publicidad dirigida a los menores de edad, encontramos que, existen leyes en materia de publicidad y competencia desleal relacionadas con el tema, y frente a la autorregulación hay un extenso desarrollo, particularmente respecto a la publicidad infantil de juguetes.

- El Código de Autorregulación de la Publicidad Infantil de Juguetes español es una regulación extensa y minuciosa, que abarca en forma detallada diversos aspectos relacionados con la publicidad sobre juguetes tales como la presentación e información de los productos, presión de ventas, apoyo y promoción a través de personajes y programas, identificación de la publicidad, presentaciones comparativas, promociones, sorteos, concursos y clubes infantiles, seguridad, educación y valores cívicos, protección de datos, y publicidad por internet y nuevas tecnologías.

- Aunque el Código de Autorregulación español mencionado se ocupa solo de la publicidad para el sector de los juguetes, hicimos una comparación entre este y las normas colombianas sobre publicidad e información dirigida a menores de edad, considerando que los temas regulados son muy similares, y que el tema específico de los juguetes queda subsumido en la regulación colombiana sobre publicidad para "productos".

- Si comparamos la regulación colombiana y española para el tema de publicidad infantil sobre productos, y específicamente sobre juguetes, vemos como el código de autorregulación español abarca con minuciosidad temas que son apenas tocados en la regulación colombiana, o que no son tocados de ninguna manera en nuestra regulación.

- Temas sobre información de productos, presión de ventas, apoyo o promoción a través de personajes, presentaciones comparativas, promociones y sorteos, seguridad, protección de datos y publicidad de juguetes, son abarcados en forma parcial o no son abarcados por el capítulo 33 del Decreto 1074 de 2015.

- Respecto al tema específico de la información sobre juguetes, el capítulo 33 del Decreto 1074 se limita a remitir al cumplimiento de lo previsto en la Resolución 3388 de 2008, la cual expide un reglamento de naturaleza técnica sobre los requisitos sanitarios de los juguetes que se comercialicen en Colombia y no se ocupa en forma directa de los temas sobre información y publicidad de los juguetes.

- Por lo anterior, consideramos que el tema de la publicidad e información sobre juguetes, -el cual entendemos como un tema de especial relevancia en la publicidad dirigida a los menores de edad-, es objeto de una escaza regulación en Colombia en comparación con la autorregulación española, al limitarse a los lineamientos generales que el decreto establece para "productos". 
- Aunque varios de los temas relevantes sobre publicidad dirigida a menores de edad que no se encuentran consagrados en el capítulo 33 del Decreto 1074 de 2015, fueron contemplados en el Código de Autorregulación colombiano que estuvo vigente hasta marzo de 2018, consideramos que, por la naturaleza misma de la autorregulación, estos temas deberían estar consagrados en normas con fuerza general vinculante.

\section{PROYECTO DE LEY N. ${ }^{\circ} 233$ DE 2017 CÁMARA "POR MEDIO DE LA CUAL SE CREAN MEDIDAS PARA REGULAR LA PUBLICIDAD DIRIGIDA A NIÑOS, NIÑAS Y ADOLESCENTES PARA LA PROTECCIÓN DE SUS DERECHOS"}

El 1 de marzo de 2017 el representante Rodrigo Lara Restrepo presentó ante la Comisión Sexta de la Cámara de Representantes de la República de Colombia el Proyecto de Ley n. ${ }^{\circ} 226$, "por medio de la cual se crean medidas para regular la publicidad dirigida a niñas, niños y adolescentes" ${ }^{\prime \prime} \mathrm{y}$ aunque este proyecto de ley fue retirado el día 16 de marzo del mismo año, ese mismo día se radicó ante la Comisión Primera Constitucional Permanente el Proyecto de Ley n. ${ }^{\circ}$ 233/2017C "Por medio de la cual se crean medidas para regular la publicidad dirigida a los niños, niñas y adolescentes para la protección de sus derechos", con contenido muy similar al del Proyecto n. ${ }^{\circ} 226$, salvo en lo relacionado con la publicidad, la cual aparecía regulada en el Proyecto $n .{ }^{\circ}$ 226, y en el Proyecto n. 233 aparecía prohibida para los niños y niñas, y regulada para los adolescentes.

El estado actual del Proyecto de Ley 233 aparece en la página web de la Cámara de Representantes como "pendiente ponencia primer debate" ${ }^{153}$ desde Junio de 2017, y en la misma página aparece publicado el documento con ponencia desfavorable para primer debate en el cual se solicita su archivo ${ }^{54}$ Sin embargo, y según tenemos entendido, dicho proyecto de ley fue retirado.

Sin embargo, y a pesar de la inactividad del mismo, este proyecto fue motivado con argumentos que valen la pena ser estudiados en aras de que su enfoque es diferente al recogido en la normatividad vigente sobre publicidad dirigida a menores de edad.

Por lo anterior, y solo para efectos meramente académicos, haremos mención a algunos de los argumentos contenidos en el informe de ponencia para primer debate del proyecto de ley, por contener, como recién lo mencionamos, un

53 Página web. Congreso de la República de Colombia. Cámara de Representantes. http:// www.camara.gov.co/publicidad-a-menores (citado en mayo 2019).

54 Ibíd. 
enfoque diferente al contemplado en las normas vigentes frente a la publicidad dirigida a los menores de catorce años.

El Informe de ponencia para primer debate del Proyecto de Ley n. ${ }^{\circ} 233$ de 2017 (en adelante, el Informe), recogió varias inquietudes con relación al tema de la publicidad dirigida a los menores de edad, dentro de las cuales se observan algunas relacionadas con el momento correcto para exponer a los niños a los mensajes publicitarios, la legislación comparada, los efectos adversos de la publicidad en los niños y el estado del arte del mercadeo dirigido a niños.

En cuanto a la regulación del tema en Colombia, el Informe mencionó en su aparte sobre "marco constitucional y legal", las disposiciones existentes sobre publicidad dirigida a menores, y cuando habló del Decreto 975 de 2014, consideró que este trata a los niños, niñas y adolescentes como consumidores y no como sujetos que requieren de protección especial, al igual que menciona que la norma se preocupa más por evitar la publicidad engañosa que por los efectos que esta pueda tener en los niños o en su salud, a diferencia del tratamiento dado al tema en otros países de la región ${ }^{55}$.

Respecto al Decreto 975, el Informe hizo la siguiente reflexión sobre la condición abusiva de la publicidad dirigida a menores en los siguientes términos: "(...) Las consideraciones de carácter ético están fuera de discusión en esta norma que no contempla en ningún caso la idea de que la publicidad para este tipo de consumidores pueda ser abusiva en sí misma" (el resaltado es nuestro $)^{56}$.

El Informe reconoció que el Decreto 975 prohíbe estrategias publicitarias que resulten nocivas para los niños, pero consideró que el tema de la alimentación es tratado de forma muy general, pudiendo ser "afinado" para evitar enfermedades y fomentar hábitos de vida saludables ${ }^{57}$.

En cuanto a la publicidad de la alimentación para menores, este es un tema muy especializado que por lo mismo merece un estudio a parte y supera el objetivo del presente escrito. Este tema es objeto de debate en varios proyectos de ley en curso, del cual resaltamos por su importancia el Proyecto de Ley 019/2017C, 256/2018S "Por medio de la cual se establecen medidas de salud pública para el control de la obesidad y otras enfermedades no transmisibles derivadas y se dictan otras disposiciones", en el cual no profundizaremos por rebasar, tal como lo mencionamos, el alcance del presente estudio.

Retomando nuestro tema, cuando el Informe menciona el Código Colombiano de Autorregulación Publicitaria, reconoce que este regula

55 Texto Ponencia primer debate. Proyecto de Ley 233 de 2017 Cámara. Por medio de la cual se crean medidas para regular la publicidad dirigida a los niños, niñas y adolescentes para la protección de sus derechos. Obtenido en http://www.camara.gov.co/publicidada-menores (citado en mayo 2019).

56 Ibíd.

57 Ibíd. 
el tema de publicidad dirigida a menores de forma más exhaustiva que el Decreto 975, pero dice que sus sanciones difícilmente tienen efecto y no son suficientemente onerosas ${ }^{58}$.

En relación con el articulado propuesto para primer debate del Proyecto de Ley $\mathrm{n}^{\circ}{ }^{\circ} 233$, este propuso en sus artículos 4 y 8, un tema novedoso en comparación con la regulación existente para el tema en Colombia, como lo es el referente a la prohibición de toda actividad de publicidad, promoción y patrocinio dirigido a niños, y la prohibición de toda actividad de publicidad, promoción y patrocinio en espacios escolares, parques públicos y lugares de recreación infantil y adolescente ${ }^{59}$.

Si observamos las normas existentes sobre el tema, esto es, la Ley 1480 de 2011, el Decreto 975 de 2014 compilado en el capítulo 33 del Decreto 1074 de 2015 y el Código Colombiano de Autorregulación Publicitaria vigente hasta marzo de 2018, ninguna de estas regulaciones prohíbe la publicidad dirigida a los niños y niñas. Más aun, todas estas normas consagran y regulan los derechos que los niños, niñas y adolescentes tienen en su calidad de consumidores, dándoles la protección especial que estos requieren.

Es así como la Ley 1480 en su artículo primero establece en cuanto a los menores de edad, que tiene como objetivos proteger, promover y garantizar la efectividad y el libre ejercicio de los derechos de los consumidores y amparar el respeto a su dignidad y a sus intereses económicos, especialmente en lo referente a la protección especial a los niños, niñas y adolescentes, en su calidad de consumidores, según lo establecido en el Código de la Infancia y la Adolescencia ${ }^{60}$.

De igual forma, la Ley 1480 consagra en su artículo 28 el derecho a la información de los niños, niñas y adolescentes concediendo al Gobierno un término para la reglamentación de los casos, el contenido y la forma en que deba ser presentada la información que se suministre a los menores en su calidad de consumidores, en desarrollo al derecho a la información consagrado en el artículo 34 de la Ley 1098 de $2006^{[61]}$.

De lo anterior se puede concluir que la Ley 1480 no solo considera a los menores como consumidores, sino que recoge el derecho de estos a recibir información en su calidad de consumidores, en desarrollo del derecho a

58 Ibíd.

59 Articulado propuesto para primer debate del Proyecto de Ley n. ${ }^{\circ} 233$ de 2017 Cámara. Por medio de la cual se crean medidas para regular la publicidad, patrocinio y promoción de productos y servicios dirigidos a los niños y adolescentes para la protección de sus derechos. Obtenido en http://www.camara.gov.co/publicidad-a-menores (citado en mayo 2019).

60 República de Colombia. Congreso. Ley 1480 (12, octubre, 2011). Por medio de la cual se expide el Estatuto del Consumidor y se dictan otras disposiciones.

61 Ibíd. 
la información consagrado en el artículo 34 del Código de la Infancia y la Adolescencia, el cual consagra el derecho que tienen los menores a buscar, recibir y difundir información e ideas a través de los distintos medios de comunicación de que dispongan, sujeto a las restricciones necesarias para asegurar su protección y el respeto de sus derechos ${ }^{62}$.

En cuanto al Decreto 975 compilado en el capítulo 33 del Decreto 1074 de 2015, este también parte de la base del derecho a la información que tienen los menores y reglamenta los casos, forma y contenido en que se debe presentar la información y la publicidad dirigida a los niños, niñas y adolescentes en su calidad de consumidores, información que debe cumplir con los lineamientos dados por el decreto, dentro de los cuales se encuentran, entre otros, el de presentar información clara, veraz, suficiente y oportuna, libre de engaño, de error, de confusión, de violencia, de discriminación, etc.

En la misma línea, el Código Colombiano de Autorregulación de la Publicidad vigente hasta marzo de 2018, reguló en su capítulo séptimo denominado "Los mensajes comerciales y los niños, niñas y adolescentes", la forma en que la información y mensajes comerciales debían ser presentados a los menores, partiendo también de la base de que los menores tienen derecho a recibir esa información.

La prohibición de los mensajes publicitarios dirigidos a los niños contenida en el Proyecto de Ley n. ${ }^{\circ} 233$ estuvo motivada en parte por las asimetrías existentes entre el contenido de la publicidad dirigida a los menores y la capacidad de estos para hacer juicios sobre sus actos de consumo, por los efectos adversos que la publicidad puede tener en los niños y por el hecho de que la responsabilidad de lo que consumen los niños es competencia primordial de los padres, conllevando lo anterior a la necesidad de expedir una nueva legislación que prohíba la publicidad dirigida a menores, por ser abusiva ${ }^{63}$. Estos argumentos fueron expuestos en las conclusiones del Informe, de las cuales transcribimos el siguiente fragmento que ilustró las razones detrás de la protección que el proyecto de ley pretendía brindar a los menores de edad frente a la publicidad:

"(...) Conclusiones. La publicidad dirigida a niños se basa en una relación asimétrica donde unas empresas con equipos de psicólogos, sociólogos, mercadotecnistas, publicistas e investigadores se enfrentan a menores que están en desventaja tanto por su carencia de capacidad por estar en procesos de desarrollo cognitivo y social, así como porque la corteza prefrontal de su cerebro no ba madurado

62 República de Colombia. Congreso. Ley 1098 (8, noviembre, 2006). Por la cual se expide el Código de la Infancia y la Adolescencia.

63 Texto Ponencia primer debate. Proyecto de Ley 233 de 2017 Cámara. Por medio de la cual se crean medidas para regular la publicidad dirigida a los niños, niñas y adolescentes para la protección de sus derechos. Obtenido en http://www.camara.gov.co/publicidada-menores (citado en mayo 2019). 
lo suficiente para tomar decisiones informadas y racionales con respecto a los actos de consumo. (...) Asimismo, en los últimos años bemos visto el ascenso de las nuevas tecnologías digitales, que ban permitido a los anunciantes acceder de manera más directa, personalizada y efectiva a los niños, por lo que la asimetría en la relación agencia de publicidad-niño se ba agudizado. La responsabilidad sobre lo que consumen los niños es competencia primordial de los padres. En este sentido, la publicidad de bienes y servicios para consumo por parte de los menores de edad debe estar dirigida a sus padres. Si los anunciantes no pueden convencer a los padres de la bondad de un producto o servicio, no se les debe permitir que se dirijan a los niños quienes, por estar en etapa de formación, son vulnerables a mensajes sobre productos que pueden resultar nocivos al mediano o largo plazo. En consecuencia, se bace necesaria una nueva legislación que probíba la publicidad dirigida a niños menores de doce (12) años, dado que es, en esencia, abusiva. En cuanto a los mayores de doce años, que ya cuentan con un mayor grado de madurez, se permitirá la publicidad, pero las técnicas utilizadas deben ser restringidas de manera que puedan ir logrando una cultura del consumo responsable. Además, dado el desarrollo de nuevas tecnologías que da a los anunciantes acceso ilimitado a los menores de edad, es necesario protegerlos de estas nuevas modalidades de publicidad y resguardar la información personal de estos de manera que se pueda dar mayor equilibrio a la relación anunciante-niños, desnaturalizada con el advenimiento de estas tecnologías. Con este fin se busca que los padres tengan la última palabra en lo que respecta al consumo, la información personal y los bábitos en línea de sus bijos, a la vez que se propone un régimen sancionatorio para que las personas naturales y jurídicas que ofrecen productos dirigidos a niños puedan llevar a cabo su actividad dentro de unos límites razonables, cuya transgresión no solo les conllevará sanciones de tipo económico, sino que los obligará a reparar a los niños, niñas y adolescentes a través de mensajes de alfabetización en medios de bábitos alimenticios y de vida saludable"64.

De lo anterior resulta evidente que el Proyecto de Ley n. ${ }^{\circ} 233$ cuestionaba el nivel de protección que la legislación vigente otorga a los niños frente al tema de la publicidad y propuso elevar esta protección a su máximo nivel prohibiéndola y poniendo de presente la necesidad de expedir nueva legislación en razón a que la publicidad dirigida a los menores es en esencia abusiva ${ }^{65}$.

Frente a este proyecto de ley, el día 13 de junio de 2017 el Representante a la Cámara por Bogotá, Samuel Hoyos Mejía, presentó ponencia desfavorable para primer debate y solicitó a los miembros de la Comisión Primera de la Cámara de Representantes el archivo del mismo ${ }^{66}$.

El texto de la ponencia de archivo en su exposición de motivos estableció que los controles a la publicidad eran necesarios para evitar que los consumidores sean engañados o sean objeto de otras malas prácticas publicitarias por lo que el estado colombiano ha hecho esfuerzos legislativos para su control, como lo son la Ley 1480 de 2011 y sus decretos reglamentarios, para proteger los intereses del consumidor, por lo que en Colombia, en procura de derechos

64 Ibíd.

65 Ibíd.

66 Texto Ponencia Primer Debate Archivo-H.R. Samuel Hoyos Junio 13 2017. Obtenido en http://www.camara.gov.co/publicidad-a-menores (citado en mayo 2019). 
fundamentales, se ha optado por adoptar mecanismos de regulación y no de prohibición de la publicidad, concluyendo que el mecanismo idóneo para proteger a los niños es la regulación y no la prohibición ${ }^{67}$.

De otra parte, el texto de la ponencia de archivo dijo que el Proyecto de Ley 233 además de prohibir la publicidad dirigida a niños, buscaba prohibir cualquier actividad empresarial dirigida a promocionar o patrocinar cualquier actividad dirigida a niños, lo que implicaría una restricción a todas las campañas de mercadeo o actividades de promoción, patrocinio y venta, violando el principio de libertad de empresa consagrado en el artículo 333 de la Constitución Política de Colombia, excediendo el verdadero objeto del proyecto ${ }^{68}$.

Los anteriores motivos, en adición a otros temas consignados en el proyecto como la prohibición de uso de datos personales y la creación de un Comité de Evaluación y de Contenidos -que requeriría el requisito de iniciativa legislativa del gobierno-, fueron los argumentos principales esgrimidos por el ponente para primer debate -Representante Samuel Hoyos Mejía-, para solicitar el archivo del Proyecto de Ley ${ }^{69}$.

Como podemos ver, este proyecto de ley y su ponencia de archivo invitaron en su momento a una discusión académica interesante en la que se cuestionaban aspectos tales como el derecho a la información y la calidad de consumidor otorgada a los niños por las leyes vigentes, el nivel de protección especial que debe otorgarse a los niños por su falta de madurez física y mental y la eventual condición abusiva de la publicidad dirigida a los menores de edad.

Este es un debate que abrió un nuevo cuestionamiento al alcance de la protección que debe brindarse a los niños, al alcance del derecho a la información que estos tienen y a las consecuencias que la publicidad puede traer a los niños. Frente a estos temas, debe ponerse en la balanza el nivel de protección que debe ser brindado a los niños por su condición especial, frente a su derecho a recibir información.

En razón a que el Proyecto de Ley 233 se encuentra inactivo, y para efectos de ver como se desenvuelven los temas relacionados con la publicidad dirigida a menores, será de interés ver el resultado que arroje el debate para el tema específico del control de la obesidad contenido en el Proyecto de Ley 019/2017C, 256/2018S que actualmente se encuentra en trámite, y que aunque tiene un alcance mucho más específico dado que se concentra en el tema del control de la obesidad, incluye en su articulado la prohibición de la promoción o publicidad de los productos de alto contenido calórico y/o bajo valor nutricional en los entornos educativos públicos y privados de educación 
prescolar, básica primaria y educación media ${ }^{70}$. El futuro desarrollo del debate en torno a este punto nos permitirá darnos una idea de cuál es la posición del legislativo frente al tema de la publicidad dirigida a menores.

\section{CONCLUSIÓN}

Dentro del escenario económico actual, los menores de edad están siendo considerados como actores importantes dentro del mercado de consumo. Tanto es así que la legislación colombiana reconoció recientemente la calidad de consumidores a este segmento de la población, al igual que le concedió varias protecciones especiales en razón a su especial condición, incluyendo dentro de estas, aquellas relacionadas con la información y publicidad dirigida a los niños, niñas y adolescentes en su calidad de consumidores.

Estos reconocimientos y protecciones especiales se encuentran plasmados en la Ley 1480 de 2011 -Estatuto del Consumidor-, y para el tema específico de la información y publicidad dirigida a los menores, en el Decreto reglamentario 975 de 2014 compilado en el capítulo 33 del Decreto 1074 de 2015; normas estas que han materializado avances significativos en el camino hacia la protección de los menores de edad en su calidad de consumidores, respetando en todo caso, su derecho a recibir información.

De igual manera, consideramos un avance muy significativo el hecho de que el tema de la información dirigida a los menores consumidores también haya sido abordado por las normas del código colombiano de autorregulación publicitaria vigente hasta marzo de 2018, y que el tema de la autorregulación publicitaria esté siendo rediseñado con el objetivo de adoptar un nuevo sistema de autorregulación expedido por la ANDA, la ANDI y otras entidades.

Sin embargo, y a pesar de los avances que estas normas representan en materia de información dirigida a los menores consumidores, se puede apreciar que las mismas abarcan el tema de forma general, quedándose cortas en la regulación de algunos temas específicos que son de importancia para el menor consumidor, dentro de los cuales se encuentran, entre otros, la publicidad para juguetes y la publicidad sobre alimentos dirigida a menores.

En particular, si comparamos las normas colombianas con el Código de Autorregulación Español de la Publicidad Infantil de Juguetes -CAPIJ-, tema sobre el cual centramos nuestro estudio comparativo, encontramos que un tema tan relevante dentro de la publicidad dirigida a menores de edad como es el tema de publicidad para juguetes, no es abordado de forma profunda en nuestra legislación, y aunque es tocado por el Código de Autorregulación

70 República de Colombia. Texto definitivo aprobado en primer debate. Proyecto de Ley 019/2017 Cámara. Por medio de la cual se establecen medidas de salud pública para el control de la obesidad y otras enfermedades no transmisibles derivadas y se dictan otras disposiciones. Artículo 10, literal e). 
colombiano vigente hasta marzo de 2018 , consideramos que merece de una más extensa protección que goce de fuerza general vinculante.

Dentro del estado actual de las cosas, lo anterior nos lleva a concluir a que, en materia de publicidad dirigida a menores de edad para juguetes, existe la necesidad de continuar con un esfuerzo legislativo mayor, que permita regular este tema de manera más exhaustiva, con mayor profundidad y con fuerza vinculante. En adición al tema de los juguetes, también vemos la necesidad de cubrir aspectos relacionados con la información sobre alimentos -tema este este que merece todo un estudio aparte por su relevancia e implicaciones en la salud de los menores-, el cual también es abordado de manera superficial.

Lo anterior en razón a que estos temas son particularmente sensibles para los consumidores menores de edad, requiriendo estos de una protección especial de categoría legal que, en nuestra opinión, y como lo comentamos anteriormente, se queda corta en la legislación colombiana actual.

De otra parte, el texto del Proyecto de Ley n. ${ }^{\circ} 233$ de 2017 -que, aunque inactivo, nos sirve de referencia académica por su enfoque especial sobre la publicidad dirigida menores-, y proyectos como el Proyecto de Ley 019/2017C-256/2018S sobre control de la obesidad -en el cual no profundizamos por superar el alcance del presente escrito-, nos invitan a hacer un cuestionamiento más serio y profundo sobre el tema de la publicidad dirigida a los menores de edad.

Es así como el Proyecto de Ley 233 cuestionó aspectos tales como la calidad de consumidor de los menores de edad otorgada por la Ley 1480 al argumentar que las decisiones de consumo de los menores son de los padres; cuestionó el derecho a la información que las leyes vigentes otorgan a los menores; consideró que la publicidad para menores es abusiva; y cuestionó el nivel de protección que las leyes vigentes otorgan a los menores frente a la publicidad dirigida a estos.

Los argumentos expuestos en este proyecto, y en iniciativas tales como el Proyecto de Ley 019/2017C-256/2018S, nos invitan a reflexionar sobre la publicidad dirigida a los menores de edad, analizando la conveniencia de elevar al nivel máximo la protección que requieren los niños frente a la publicidad, esto es, prohibirla; o si por el contrario, debe prevalecer el derecho a recibir información que tienen los niños en las leyes vigentes, con las restricciones y protecciones que se requieren para proteger los derechos de estos en su calidad de consumidores menores de edad.

\section{BIBLIOGRAFÍA}

República de Colombia. Asamblea Nacional Constituyente. Constitución Política de Colombia,1991. 
República de Colombia. Decreto 3466 (2, diciembre 1982). "Por el cual se dictan normas relativas a la idoneidad, la calidad, las garantías, las marcas, las leyendas, las propagandas y la fijación pública de precios de bienes y servicios, la responsabilidad de sus productores, expendedores y proveedores, y se dictan otras disposiciones".

República de Colombia. Congreso de la República. Ley 1098 (8, noviembre, 2006). "Por la cual se expide el Código de la Infancia y la Adolescencia".

República de Colombia. Congreso de la República. Ley 12 (22, enero, 1991). "Por medio de la cual se aprueba la Convención sobre los Derechos Del Niño adoptada por la Asamblea General de las Naciones Unidas el 20 de noviembre de 1989".

República de Colombia. Resolución 3388 de 2008. "Por la cual se expide el reglamento técnico sobre los requisitos sanitarios de los juguetes, sus componentes y accesorios, que se comercialicen en el Territorio Nacional, y se dictan otras disposiciones".

República de Colombia. Congreso de la República. Ley 1480 (12, octubre, 2011). "Por medio de la cual se expide el Estatuto del Consumidor y se dictan otras disposiciones".

República de Colombia. Ministerio de Comercio, Industria y Turismo. Decreto 975 (28, mayo, 2014). Por el cual se reglamentan los casos, el contenido y la forma en que se debe presentar la información y la publicidad dirigida a los niños, niñas $\mathrm{y}$ adolescentes en su calidad de consumidores.

República de Colombia. Ministerio de Comercio, Industria y Turismo. Decreto 1074 (26, mayo, 2015). Por medio del cual se expide el Decreto Único Reglamentario del Sector Comercio, Industria y Turismo.

República de Colombia. Proyecto de Ley 233 de 2017 Cámara. Por medio de la cual se crean medidas para regular la publicidad dirigida a los niños, niñas y adolescentes para la protección de sus derechos.

República de Colombia. Texto Ponencia primer debate. Proyecto de Ley 233 de 2017 Cámara. Por medio de la cual se crean medidas para regular la publicidad dirigida a los niños, niñas y adolescentes para la protección de sus derechos. Obtenido en http://www.camara.gov.co/publicidad-a-menores.

República de Colombia. Texto definitivo aprobado en primer debate. Proyecto de Ley 019/2017 Cámara "Por medio de la cual se establecen medidas de salud pública para el control de la obesidad y otras enfermedades no transmisibles derivadas y se dictan otras disposiciones".

España. Ley 34/1988, de 11 de noviembre. "Ley General de Publicidad". 
España. Ley 29/2009, de 30 de diciembre, "Por la que se modifica el régimen legal de la competencia desleal y de la publicidad para la mejora de la protección de los consumidores y usuarios".

Unión Europea. Directiva 2005/29/CE. Del Parlamento Europeo y del Consejo. (11, mayo, 2005). Relativa a las prácticas comerciales desleales de las empresas en sus relaciones con los consumidores en el mercado interior, que modifica la Directiva 84/450/CEE del Consejo, las Directivas 97/7/CE, 98/27/CE y 2002/65/ CE del Parlamento Europeo y del Consejo y el Reglamento (CE) no. 2006/2004 del Parlamento Europeo y del Consejo.

Unión Colombiana de Empresas Publicitarias UCEP. (en línea). http://www.ucepcol.com

Unión Colombiana de Empresas Publicitarias UCEP. (en línea) http://www.ucepcol. $\mathrm{com} / \#$ !codigoautorregulacion/c4fn

Comisión Nacional de Autorregulación Publicitaria, CONARP. Código Colombiano de Autorregulación Publicitaria. (en línea) http://media.wix.com/ugd/3455e7_ 799d2f146d164ab79a620ee0e95e3b5b.pdf

Asociación Española de Fabricantes de Juguetes y Unión de Consumidores de España. Código Deontológico para Publicidad Infantil. (en línea). http://docplayer. es/3855230-Codigo-deontologico-para-publicidad-infantil.html

Asociación Española de Fabricantes de Juguetes. Código de Autorregulación de la Publicidad Infantil de Juguetes. (en línea). https://www.aefj.es/contenidos/codigode-autorregulacion-de-la-publicidad-infantil-de-juguetes (citado en mayo 2019).

https://robertoigarza.files.wordpress.com/2008/11/rep-the-now-generation-caracterizacion-datos-y-perfiles-sociales-infantiles-aiju-2011.pdf

http://winred.com/marketing/marketing-infantil-el-consumidor-de-hoy-y-de-manana/ gmx-niv115-con1729.htm

http://www.redalyc.org/articulo.oa?id=199519981063

http://alternation.ukzn.ac.za/Files/docs/14.1/07\%20Cassim.pdf 